\title{
WNT-5A: signaling and functions in health and disease
}

\author{
Kuldeep Kumawat $^{1,2} \cdot$ Reinoud Gosens ${ }^{1,2}$
}

Received: 1 September 2014/Revised: 13 October 2015/ Accepted: 15 October 2015/Published online: 29 October 2015

(C) The Author(s) 2015. This article is published with open access at Springerlink.com

\begin{abstract}
WNT-5A plays critical roles in a myriad of processes from embryonic morphogenesis to the maintenance of post-natal homeostasis. WNT-5A knock-out mice fail to survive and present extensive structural malformations. WNT-5A predominantly activates $\beta$-catenin-independent WNT signaling cascade but can also activate $\beta$-catenin signaling to relay its diverse cellular effects such as cell polarity, migration, proliferation, cell survival, and immunomodulation. Moreover, aberrant WNT-5A signaling is associated with several human pathologies such as cancer, fibrosis, and inflammation. Thus, owing to its diverse functions, WNT-5A is a crucial signaling molecule currently under intense investigation with efforts to not only delineate its signaling mechanisms and functions in physiological and pathological conditions, but also to develop strategies for its therapeutic targeting.
\end{abstract}

Keywords Transcription - Receptors - Embryogenesis · Migration · Differentiation - Fibrosis - Cancer · Inflammation

Kuldeep Kumawat

kumawatkuldeep@hotmail.com;

k.kumawat@rug.nl

1 Department of Molecular Pharmacology, University of Groningen, Antonius Deusinglaan 1, 9713 AV Groningen, The Netherlands

2 Groningen Research Institute for Asthma and COPD, University of Groningen, Groningen, The Netherlands

\section{Introduction}

WNT-5A is a member of the Wingless/integrase 1 (WNT) family of secreted glycoproteins. In humans, 19 WNT proteins (WNTs) are currently known that act as ligands for several membrane-bound receptors which includes 10 class Frizzled receptors (FZD), low-density lipoprotein receptorrelated protein (LRP) 5/6 co-receptors, and many non-class FZD receptors, such as ROR1, ROR2, RYK, and PTK7 [1]. The intracellular WNT signaling is broadly classified into two main branches- $\beta$-catenin-dependent (canonical) and $\beta$-catenin-independent (non-canonical) WNT signaling. Due to the complexity and vast diversity of downstream signaling, the canonical and non-canonical nomenclature has become outdated. WNT/ $\beta$-catenin signaling is initiated by binding of a WNT to a class FZD receptor and LRP5/6 co-receptors concluding a multimeric membrane signaling complex which results in the stabilization and cytosolic accumulation of transcriptional co-activator $\beta$-catenin. Ultimately, the stabilized $\beta$-catenin translocates to the nucleus where it associates with the T-cell factor/lymphoid enhancer-binding factor (TCF/LEF) transcription factors and activates WNT-target gene transcription [1]. In contrast, the $\beta$-catenin-independent signaling branches function independent of $\beta$-catenin and LRP5/6 and activate various signaling cascades involved in the regulation of cell polarity and movements, cytoskeletal reorganization, and gene transcription. Two of the best characterized $\beta$ catenin-independent WNT signaling pathways are the $\mathrm{WNT} / \mathrm{Ca}^{2+}$ and $\mathrm{WNT} /$ planar cell polarity (PCP) pathways. The WNT/Ca ${ }^{2+}$ signaling pathway involves activation of $\mathrm{Ca}^{2+}$-dependent signaling molecules, including protein kinase $\mathrm{C}$ (PKC), $\mathrm{Ca}^{2+} /$ calmodulin-dependent protein kinase II (CaMKII), and nuclear factor of activated $\mathrm{T}$ cell (NFAT), whereas the WNT/PCP pathway is mediated by 
RhoA signaling or activation of c-Jun N-terminal Kinases (JNKs) via small Rho-GTPases [2]. The WNT/Ca ${ }^{2+}$ pathway can also antagonize WNT/ $\beta$-catenin signaling by phosphorylation of TCF/LEF transcription factors via activation of the TGF- $\beta$-activated kinase 1 (TAK1)-Nemolike Kinase (NLK) cascade [3].

WNT-5A, a prototypical WNT of $\beta$-catenin-independent branch, is highly conserved among species and plays key roles in the processes governing embryonic development, post-natal tissue homeostasis, and pathological disorders throughout the lifespan of an organism (Fig. 1) [4, 5]. Homozygous WNT-5A knock-out mice show perinatal lethality, primarily due to respiratory failure, and present extensive developmental abnormalities. It is involved in lung [6], heart [7], and mammary gland morphogenesis [8] and regulates stem cell renewal $[9,10]$, osteoblastogenesis $[11,12]$, and tissue regeneration [13]. In addition, aberrant WNT-5A expression and signaling is associated with various malignancies [14] and proinflammatory responses [15] as well as with lung [16], renal [17], and hepatic [18] fibrosis. WNT-5A signaling has also been implicated in ciliopathies [19] and WNT-5A antagonism counteracts vascular calcification [20]. We have recently reported increased WNT-5A expression in asthmatic airway smooth muscle cells [21] and have demonstrated that TGF- $\beta$ induces WNT-5A expression in airway smooth muscle cells where it mediates expression of extracellular matrix proteins (ECM) [21] and participates in airway remodeling in asthma.

In view of the plethora of evidence associating WNT-5A with health and disease, there is considerable interest in understanding its biology. In this review, we discuss our current understanding of various aspects of WNT-5A signaling and its functions derived from studies in wide variety of in vivo models including Drosophila, Xenopus, and mouse; in vitro cell-based systems and patient-based reports.

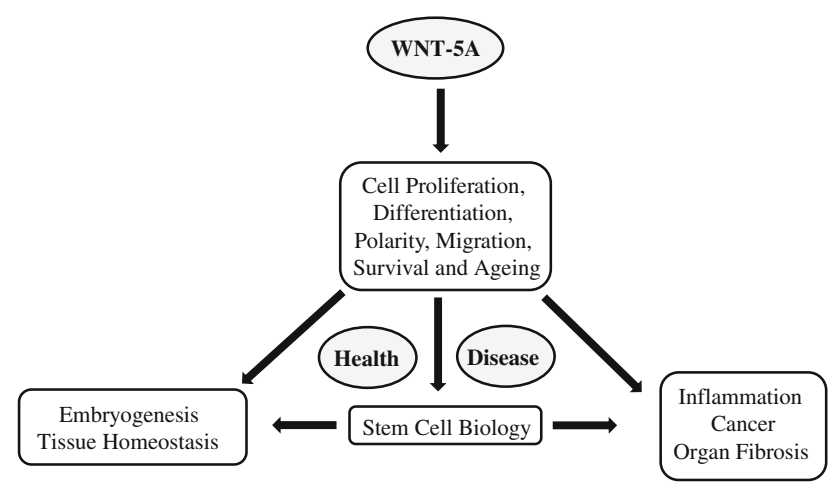

Fig. 1 WNT-5A in health and disease. A schematic representation of key functions and pathologies associated with WNT-5A

\section{WNT-5A gene}

WNT-5A cDNA was first isolated from mouse fetal tissue [22] followed by the isolation and sequencing from human cells [23]. The human WNT-5A gene is located on chromosome 3p14-p21. The WNT-5A gene generates two very identical transcripts by utilization of alternative transcription start sites and the corresponding upstream sequences are termed as promoter A and B [24] and their products as WNT-5A-L and WNT-5A-S, respectively [25]. Both the promoters have comparable transcriptional potential; their activity, however, is highly context dependent. WNT-5A promoter $\mathrm{A}$ has been suggested to be more active in human and murine fibroblasts as compared to promoter B [26]. Both the isoforms have similar biochemical properties such as stability, hydrophobicity, and signaling activity [25]. While the significance of individual WNT-5A isoforms is not completely understood, and it is not entirely clear whether they are functionally redundant, a recent study showed that they might have different functions [25]. When ectopically expressed, WNT-5A-L inhibited proliferation of various cancer cells lines, whereas WNT-5A-S leads to stimulation of growth [25].

\section{WNT-5A transcription}

WNT-5A is a transcriptional target of an array of cytokines and growth factors. CUTL1 [27], STAT3 [28], TBX1 [29], and $\mathrm{NF \kappa B}[30,31]$ have been reported as transcription factors for WNT-5A in various cell types. We have recently shown that TGF- $\beta$ induces expression of WNT-5A by engaging p38 and JNK signaling via TAK1 in airway smooth muscle cells [32]. This leads to the stabilization of $\beta$-catenin which then interacts with Sp1. Sp1, in turn, binds to the WNT-5A promoter and drives its expression [32]. TGF- $\beta$ has also been shown to induce WNT-5A expression in mammary glands [8], primary fibroblasts [8], primary epithelial cells [8], and pancreatic cancer cells [27]. Similarly, proinflammatory factors such as interleukin (IL)-1 $\beta$ [31], tumor necrosis factor- $\alpha$ (TNF- $\alpha$ ) [30], lipopolysaccharide (LPS)/interferon $\gamma$ (IFN $\gamma)$ [15], IL-6 family members-leukemia inhibitory factor (LIF) and cardiotrophin-1 (CT-1) [33], and high extracellular calcium concentration [34] all augment, whereas amino acid limitation [35] represses WNT-5A expression in various cell types. Collectively, this suggests that WNT-5A is a target of TGF- $\beta$ and proinflammatory signaling which will be discussed below.

Interestingly, WNT-5A is also regulated at translational level via the numerous AU-rich motifs which are present in the evolutionary conserved $3^{\prime}$-untranslated region of mRNA [36]. AU-rich element binding proteins (ARE- 
binding proteins) associate with the AREs and tightly regulate their stability by posttranscriptional mechanisms. HuR, a member of embryonic lethal abnormal vision (ELAV) -like family of ARE-binding proteins, binds to the $3^{\prime}$-UTR AREs in WNT-5A mRNA and suppresses its translation [36].

\section{WNT-5A protein}

WNT-5A-L and WNT-5A-S, composed of 380 and 365 amino acids, respectively, are heavily glycosylated and lipid-modified proteins. Each isoform consists of an N-terminal hydrophobic signal sequence, a conserved asparagine-linked oligosaccharide consensus sequence and about 22 highly conserved cysteine residues (Fig. 2a, b) [23]. Cleavage of the N-terminal signal sequence is predicted to generate mature protein containing either 343 or 338 amino acids [25]. However, $\mathrm{N}$-terminal sequencing of mature WNT-5A isoforms revealed that WNT-5A-L is cleaved after the 43rd amino acid, whereas WNT-5A-S has much longer signal sequence with cleavage after the 46th amino acid, generating mature proteins containing 337 and 319 amino acids, respectively (Fig. 2a, b) [25]. Interestingly, mouse WNT-5A which is $\sim 99 \%$ homologous to human WNT-5A generates same mature protein as human WNT-5A-S [37]. In mouse WNT-5A, asparagine 114, 120, 311 , and 325 have been identified as the N-linked glycosylation sites, whereas a palmitoylation has been identified at cysteine 104. The palmitoylation of WNT-5A is necessary for its binding to $\mathrm{FZD}_{5}$ and signaling activity but not required for its secretion $[38,39]$. In contrast, glycosylation of WNT-5A is required for its secretion but dispensable for its signaling activity [38].

\section{WNT-5A: receptors and signaling}

WNT-5A binding to receptor activates various $\beta$-cateninindependent signaling cascades; however, it can also activate $\mathrm{WNT} / \beta$-catenin signaling depending on the cell- and receptor-context. WNT-5A can signal through multiple receptors and according to current understanding $\mathrm{FZD}_{2}$, $\mathrm{FZD}_{3}, \mathrm{FZD}_{4}, \mathrm{FZD}_{5}, \mathrm{FZD}_{6}, \mathrm{FZD}_{7}, \mathrm{FZD}_{8}, \mathrm{RYK}, \mathrm{ROR} 2$, and CD146 may function as WNT-5A receptors [34, 37, 40-50].

WNT-5A has been shown to bind to $\mathrm{FZD}_{2}$ inducing intracellular calcium release and PKC activation in Xenopus [51] and zebrafish embryos [52] and WNT-5A-FZD ${ }_{2}$ induced calcium spikes in neurons are implicated in traumatic brain injury [53]. WNT-5A binds to $\mathrm{FZD}_{2}$ in a ROR1- or ROR2-dependent manner and recruits Disheveled (DVL) and $\beta$-arrestin to $\mathrm{FZD}_{2}$ leading to the clathrinmediated internalization of $\mathrm{FZD}_{2}$ [40]. Internalization of
$\mathrm{FZD}_{2}$ is essential for WNT-5A-induced Rac activation [40]. WNT-5A also induces clathrin-mediated internalization of $\mathrm{FZD}_{4}$ [54] in a PKC- and $\beta$-arrestin-dependent process and that of ROR2 in a PKC-dependent manner [47]. Similarly, binding of WNT-5A to FZD $_{5}$ also leads to its internalization [38]. Internalization of receptors is considered as a critical step in WNT signaling and a reflection of active signaling. Although the exact mechanisms underlying the functional significance of receptor internalization are not clear, it is believed to facilitate intracellular signaling activation by recruitment of scaffolding proteins such as $\beta$-arrestin and may also facilitate the termination of signaling and receptor recycling [55].

We have recently demonstrated that WNT-5A signals through $\mathrm{FZD}_{8}$ and $\mathrm{RYK}$ receptors leading to the activation of $\mathrm{Ca}^{2+}$-NFATc1 and JNK signaling which mediates TGF$\beta$-induced ECM expression in airway smooth muscle cells [21]. WNT-5A binding to $\mathrm{FZD}_{7}$ activates prosurvival $\mathrm{PI} 3 \mathrm{~K} / \mathrm{AKT}$ cascade in human melanoma cells which can account for the resistance of these cells to BRAF inhibitors [48]. Similarly, WNT-5A can activate the PI3K/AKT cascade via $\mathrm{FZD}_{3}$ in human dermal fibroblasts and promotes integrin-mediated adhesion of these cells [41]. In contrast, WNT-5A-activated PI3K/AKT signaling induces migration in human osteosarcoma cells [56]. Similarly, WNT-5A induces migration in gastric cancer cells by activating PI3K/AKT pathway which phosphorylates and inactivates GSK-3 $\beta$ and activates RhoA leading to cytoskeleton remodeling [57]. Indeed, cytoskeletal reorganization and cell migration are major cellular effects of WNT-5A signaling.

WNT-5A is proposed to regulate cell fate via $\mathrm{FZD}_{6}$ in hair follicles [50], whereas it plays critical role in tuberculosis immunology via $\mathrm{FZD}_{5}$ regulating immune responses by antigen presenting cells and activated $\mathrm{T}$ cells in response to mycobacterium infection [42].

The FZDs belong to the class of seven transmembranespanning G protein-coupled receptors. Recent evidence shows a role for heterotrimeric G proteins in WNT-5A downstream signaling. For instance, $G$ proteins are required for WNT-5A-induced JNK and NFKB activation in human neutrophils [58]. Similarly, WNT-5A activates $\mathrm{G}_{\alpha \mathrm{i} / \mathrm{o}}$ proteins leading to $\mathrm{Ca}^{2+}$-dependent ERK1/2 activation in murine primary microglia [59] and HEK293 cells [60]. A recent study has shown that Daple (DVL-associating protein with a high frequency of leucine residues) functions as a non-receptor Guanine nucleotide exchange factor in WNT signaling which interacts and activates $\mathrm{G}_{\alpha \mathrm{i}}$ in response to WNT-5A stimulation [61]. This indicates that G protein coupling by FZDs is clearly a relevant physiological phenomenon, but whether coupling with heterotrimeric G proteins in FZD signaling is an absolute requirement or context-dependent remains unclear [62]. 
A

WNT-5A-I WNT $-5 A-S$

WNT-5A-I WNT-5A-S

WNT-5A-I WNT-5A-S

WNT-5A-L WNT-5A-S

WNT-5A-L WNT-5A-S

WNT-5A-L WNT-5A-S

WNT-5A-L WNT-5A-S
MKKSIGILSPGVALGMAGSAMSSKFFLVALAIFFSFAQVVIEANSWWSLGMNNPVQMSEV -MAGSAMSSKFFLVALAIFFSFAQVVIEANSWWSLGMNNPVQMSEV

104

114

YIIGAQPLCSQLAGLSQGQKKLCHLYQDHMQYIGEGAKTG IKECQYQFRHRRWNCSTVDN 120 YI IGAQPLCSQLAGLSQGQKKLCHLYQDHMQYIGEGAKTG IKECQYQFRHRRWNCS TVDN 105 1

TSVFGRVMQIGSRETAFTYAVSAAGVVNAMSRACREGELSTCGCSRAARPKDLPRDWLWG TSVFGRVMQIGSRETAFTYAVSAAGVVNAMSRACREGELSTCGCSRAARPKDLPRDWLWG

GCGDNI DYGYRFAKE FVDARERERI HAKGSYESARI LMNLHNNEAGRRTVYNLADVACKC GCGDNIDYGYRFAKE FVDARERERI HAKGSYESARI LMNLHNNEAGRRTVYNLADVACKC

HGVSGSCSLKTCWLQLADFRKVGDALKEKYDSAAAMRLNSRGKLVOVNSRFNSPTTQDLV $\mathbf{3 0 0}$ HGVSGSCSLKTCWLQLADFRKVGDALKEKYDSAAAMRLNSRGKLVQVNSRFNSPTTQDLV $\mathbf{2 8 5}$

312 326

YIDPSPDYCVRNESTGSLGTQGRLCNKTSEGMDGCELMCCGRGYDQFKTVQTERCHCKFH $\mathbf{3 6 0}$ YIDPSPDYCVRNESTGSLGTQGRLCNKT SEGMDGCELMCCGRGYDQFKTVQTERCHCKFH $\mathbf{3 4 5}$

B

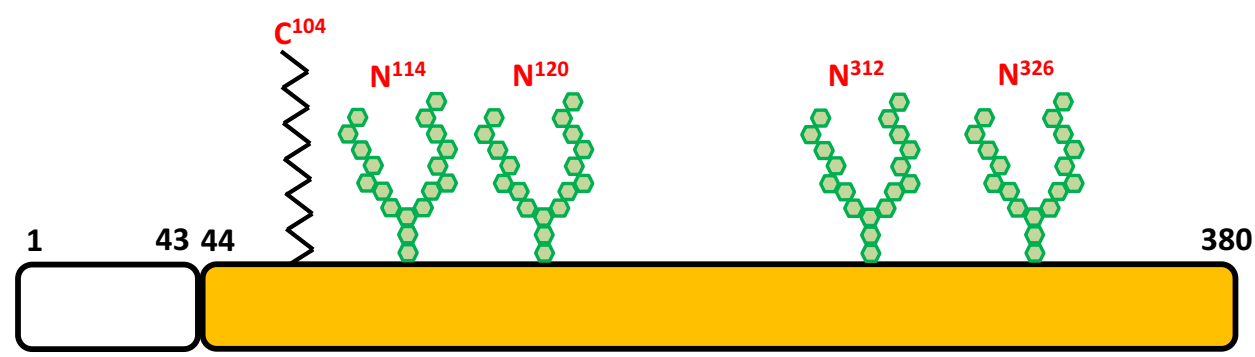

Fig. 2 WNT-5A protein. a A comparative analysis of amino acid sequences of human WNT-5A-L and WNT-5A-S isoforms. Gray highlighted area represents $\mathrm{N}$-terminal signal sequence in respective protein. Bold arrows mark the site of signal sequence cleavage and $\mathrm{N}$-terminus of respective mature protein. The amino acids marked in red-bold represent posttranslational modification sites on protein backbone. Number represents the respective position of the amino acid from the first $\mathrm{N}$-terminal amino acid. The protein sequences are

WNT-5A also binds to non-class FZD receptors including ROR2 and RYK receptor tyrosine kinases. ROR2 is a key receptor for WNT-5A-induced effects during development as demonstrated by remarkable phenotypic resemblance between the ROR2 and WNT-5A knock-out mice [63]. Multiple mechanisms have been suggested to explain the close functional relationship between WNT-5A and ROR2. WNT-5A interacts with ROR2 and VANGL2 to form a ternary complex leading to the casein kinase $1 \delta$ (CK1 $\delta$ )-induced phosphorylation of VANGL2 which serves to relay the gradient effects of WNT-5A, thereby regulating WNT-5A-induced planar cell polarity and taken from NCBI: NP_003383.2 (WNT-5A-L) and NP_001243034.1 (WNT-5A-S). b Diagrammatic representation of WNT-5A-L protein. $\mathrm{N}$-terminal signal sequence is represented by blank box. ₹ represents palmitoylation and $\$ 8$ represents $\mathrm{N}$-linked glycosylation on the protein backbone. The respective amino acids locations are marked above the modification sites. The N-linked glycosylation sites N312 and N326 correspond to N311 and N325 of mouse WNT-5A, respectively

embryonic morphogenesis [64]. WNT-5A associates with $\mathrm{FZD}_{7}$ in the presence of ROR2 to form a complex required for DVL polymerization and activation of Rac-dependent WNT signaling [49]. WNT-5A activates ERK1/2 in intestinal epithelial cells via ROR2 [65], whereas it activates JNK-mediated c-Jun transcriptional activity to induce production of receptor activator of nuclear factor- $\kappa \mathrm{B}$ (RANK), a regulator of osteoclast differentiation and activation, in osteoclast precursor cells via ROR2 [11]. WNT-5A engages ROR2 to activate JNK signaling and regulates cell movement [4, 66-68], whereas it induces assembly of DVL-atypical PKC (aPKC) and polarity 
complex (PAR3 and PAR6) to regulate neuronal differentiation and polarity $[69,70]$. Thus, ROR2 participates in several key cellular functions of WNT-5A.

WNT-5A activates intracellular calcium release to fine tune neuronal growth by axonal outgrowth and repulsion. WNT-5A signals via RYK leading to calcium release from stores through $\mathrm{IP}_{3}$ receptors as well as calcium influx through transient receptor potential (TRP) channels inducing axonal outgrowth. On the other hand, simultaneous association of WNT-5A with RYK and FZD releases calcium from TRP channels without involvement of $\mathrm{IP}_{3}$ receptors and induces axonal repulsion [71]. WNT-5A also forms a ternary complex with RYK and VANGL2 to relay the WNT/PCP effects [72], whereas WNT-5A-RYK signaling is required for inhibition of reactive oxygen species (ROS) production and maintenance of hematopoietic stem cell quiescence [73].

Recently, WNT-5A binding to an adhesion molecule CD146 has also been described, leading to the recruitment of DVL2 to the complex and activation of downstream JNK signaling cascade [45]. CD146 has been linked to cell migration via RhoA-dependent cytoskeletal rearrangements [74]. In line with that, WNT-5A-CD146 axis regulates polarity and migration of cells $[45,75]$.

\section{Effects of WNT-5A on $\beta$-catenin signaling}

Interestingly, in addition to activating the $\beta$-catenin-independent WNT pathway, WNT-5A can also have positive or negative regulatory effects on $\mathrm{WNT} / \beta$-catenin signaling depending on the receptor- and cell-context. Indeed, a study has shown that WNT-5A can both activate and inhibit $\beta$-catenin-dependent WNT signaling during mouse embryonic development [76]. WNT-5A knock-out embryos show increased $\beta$-catenin activation in telencephalon and embryonic fibroblasts from WNT-5A knockout animals show heightened response to WNT3A, a prototypical $\beta$-catenin-dependent signaling WNT [40]. Another study demonstrated that WNT-5A competes with WNT-3A for binding to $\mathrm{FZD}_{2}$, a receptor for both the WNTs, thereby inhibiting the WNT-3A-induced $\beta$-catenin signaling [40]. The WNT-5A-activated CaMKII-TAK1NLK1 cascade has been implicated in $\mathrm{WNT} / \beta$-catenin suppression [3]. In addition, WNT-5A inhibits WNT-3Ainduced $\beta$-catenin signaling via ROR2 and CD146 [37, 45]. In hematopoietic stem cells, WNT-5A inhibits $\beta$-catenin signaling supposedly via suppression of ROS production [73]. Similarly, WNT-5A inhibits $\beta$-catenin signaling by promoting its degradation through an alternative E3 ubiquitin ligase complex composed of siah2-APC-Ebi [77]. Purified WNT-5A, on the other hand, can activate $\beta$-catenin-dependent transcription in the presence of $\mathrm{FZD}_{4}$ and
LRP5 [37, 46]. Also, WNT-5A activates $\beta$-catenin signaling in pancreatic cancer cells [27, 78] and dermal fibroblasts [79]. Similarly, osteoblast-lineage cells from WNT-5A knock-out mice show reduced WNT/ $\beta$-catenin signaling and WNT-5A pre-treatment potentiated the WNT/ $\beta$-catenin signaling in bone marrow stromal cells via upregulation of LRP5 and LRP6 expression [80].

\section{Functions of WNT-5A}

\section{Embryogenesis}

WNT-5A has been identified for its key involvement in defining the body outgrowths in addition to many other specific features. WNT-5A expression is most abundant during early embryonic developmental stages between 10-14 days post conception [5, 22]. Importantly, homozygous WNT-5A knock-out mouse embryos show perinatal lethality underlining its vital role in embryogenesis. During development, regions undergoing extensive outgrowth like limbs, tail, and facial structures exhibit prominent WNT-5A expression where it is present in a graded fashion with the highest abundance at the tips of these structures and lowest in the proximal areas [5, 22]. WNT-5A knock-out leads to severe malformations in the outgrowth structures, a shortened anterior-posterior (A-P) and severely compromised proximal-distal (P-D) body axis. These malformations could be traced back to the underlying axial skeleton which exhibited a shortened vertebral column due to smaller vertebrae size and the absence of caudal vertebrae. The phenotype apparently originates from the critical role of WNT-5A as a mitogen required for the proliferation of the mesodermal progenitors early in embryonic development. The mesodermal stem cells which arise early in development can continue to develop in the primitive streak even in the absence of WNT-5A but lack the ability to divide and give rise to the progeny. Impaired self-renewal capacity leads to progressive depletion of the stock of these stem cells resulting in insufficient numbers of cells to develop the distal skeleton and leading to the absence of related structures [5].

Similar to WNT-5A knock-out mice, WNT-5A transgenic mice show perinatal lethality when WNT-5A is induced early in development exhibiting severe deformities resembling the WNT-5A knock-out phenotype [81]. Overexpression of WNT-5A induced malformations of limbs, tail, and facial structures. Underdeveloped limb skeletal elements, reduced number of tail vertebrae, and shortened upper and lower jaw bones constituted the mutant phenotype. Interestingly, overexpression of WNT$5 \mathrm{~A}$ in later embryonic stages and in adult animals was well tolerated with no visible phenotype [81]. This study 
highlights a critical window during embryonic development when WNT-5A activity is most required [81].

Further studies have looked into the organ-specific developmental roles of WNT-5A and have identified a crucial role for distal morphogenesis of internal organs. For instance, WNT-5A knock-out mice fail to develop the genital tubercle [5] and have intestinal deformities [82]. Prominent WNT-5A expression is observed in the gut mesenchyme during intestinal morphogenesis which persists throughout the development of the small intestine [5, 83]. In line with that, WNT-5A knock-out mice show severe malformations in the small intestine with drastically reduced length and the presence of a secondary cavity. In addition, the mutants present an imperforated anus [82]. Interestingly, overexpression of WNT-5A during embryonic development also leads to gut malformations resembling the WNT-5A knock-out phenotype. Specifically, WNT-5A transgenic mice show shortening of the small and large intestine, caecum, and stomach and also present anal imperforation [81]. Of note, both the loss and overexpression of WNT-5A does not interfere with the intestinal differentiation or cell fate decisions. The underlying mechanisms that lead to the malformations observed in WNT-5A transgenic mice are not clear yet. However, the observation that overexpression of WNT-5A leads to the downregulation of ROR2 in intestine [81] could reveal the reason behind the similarities in both the WNT-5A transgenic and knock-out phenotypes. ROR2 is a receptor for WNT-5A and ROR2 knock-out mice show a phenotype resembling that of WNT-5A knock-out [63]. Therefore, increased expression of WNT-5A which leads to the downregulation of ROR 2 could present a similar phenotype as ROR2 knock-out. Although the downstream WNT-5A signaling after overexpression remained intact, it is tempting to speculate that ROR2-dependent WNT-5A signaling is crucial for the embryonic development and that the loss of ROR2 in WNT-5A transgenic mice underlies the similarity with the WNT-5A knock-out phenotype.

Convergent extension (CE) is the critical morphogenetic movement during gastrulation wherein the germ layers narrow down mediolaterally resulting in the elongation of embryo from head to tail and shaping of body axis [84]. CE requires collective cell migration and cell intercalations. WNT-5A-activated signaling has been associated with CE movements [85-87] owing to its ability to regulate cell migration and polarity (as discussed in this review). Thus, embryonic structural abnormalities in WNT-5A knock-out and transgenic mice may not only arise from impaired proliferation but also due to derailed CE movements.

Lungs are complex organs with extensive branching, a large number of different types of specialized cells, and distinct P-D polarity. WNT-5A, as a major determinant of $\mathrm{P}-\mathrm{D}$ polarity, is prominently expressed in the embryonic lungs $[6,22]$ where it is localized in both the mesenchymal and epithelial compartments. WNT-5A signaling is most enhanced at the tip and around the branching epithelium [6]. In later stages, WNT-5A is predominantly localized to the lung epithelium and attains a typical P-D gradient with most expression in the distal branching epithelium and almost no presence in the proximal regions [6]. Analysis of lungs obtained from WNT-5A knock-out mice revealed extensive developmental malformations. The trachea was truncated with reduced number of cartilages [6]. The branching morphogenesis of WNT-5A knock-out lungs was compromised as revealed by the increased number and overexpansion of terminal airways. Also, the intersaccular walls were thick and hypercellular indicating failed maturation of lungs in WNT-5A knock-out embryos. Further analysis revealed that loss of WNT-5A did not interfere with cell differentiation but led to hyperproliferation resulting in intersaccular septum thickening and disrupted vasculature [6]. Interestingly, WNT-5A knock-out lungs presented increased expression of sonic hedgehog/patched (SHH/PTC), fibroblast growth factor (FGF), and bone morphogenetic protein(BMP)-4 indicating the molecular mechanisms involved in the observed WNT-5A knock-out phenotype [6]. Notably, lungs of WNT-5A knock-out mice show resemblance with the FGF-10 knock-out [88], SHH knock-out [89, 90], SHH transgenic [91], and BMP-4 transgenic [92] lung phenotype, which underlines the interactive network of WNT-5A, FGF-10, SHH/PTC, and BMP-4 in lung development. Lung-specific WNT-5A transgenic expression also disrupts lung morphogenesis as demonstrated by dilated terminal airways, loss of branching, and smaller size of the lungs [93]. Interestingly, supporting a role for WNT-5A in regulating other signaling cascades, WNT-5A overexpression repressed SHH/PTC expression and distribution in the lung epithelium, whereas it augmented FGF-10 abundance in the mesenchyme [93]. While FGF-10 expression is increased, WNT-5A overexpression severely impairs the ability of epithelium to respond to FGF-10 [93]. Thus, WNT-5A fine-tunes the developmental signaling underlying the epithelial-mesenchyme communication which is required for proper lung morphogenesis [93].

WNT-5A expression is crucial for proper neuronal generation and axonal guidance during embryonic development and in post-natal life. WNT-5A knock-out mice show anomalies in the dopaminergic midbrain neuronal morphogenesis, organ innervation, and show increased neuronal apoptosis $[94,95]$. Robust WNT-5A expression is detected in ventral midbrain where it promotes dopaminergic neurite and axonal growth [95]. In fact, WNT-5A promotes and cooperates with $\mathrm{WNT} / \beta$-catenin signaling to generate midbrain dopaminergic neurons in vivo and in stem cells $[39,96]$, whereas WNT-5A expression in the 
sympathetic neurons is crucial for axonal branching for proper organ innervation via ROR1 and ROR2 receptors $[63,94]$. WNT-5A can also signal via RYK to mediate cortical axonal growth and guidance [43, 71]. The absence of axonal guidance in both the ROR1/2- and RYK-deficient mice shows their function is non-redundant and the utilization of respective receptors may be context dependent.

WNT-5A is also required for proper cardiac morphogenesis as WNT-5A knock-out mice show severe defects in the septation of the cardiac outflow tract (OFT) [97]. OFT originates from an embryonic region called second heart field (SHF) which functions as a source of progenitor cells for development of most of the heart. WNT-5A is expressed in the pharyngeal mesoderm adjacent to cardiac neural crest cells in both mouse and chicken embryos and in the myocardial cell layer [97]. WNT-5A expression is induced in SHF by a transcription factor-TBX1 and loss of WNT-5A results in severe decline in the number of SHF progenitor cells and deployment of these progenitors to the OFT leading to cardiac deformities [7, 29, 98].

In summary, WNT-5A signaling is crucial to the development of internal organs and the formation of skeletal structures. Of importance, WNT-5A cooperates with other WNTs (e.g., WNT-11) and several non-WNT morphogens involved in development including TGF- $\beta$, BMPs, FGFs, and SHH signaling [8, 93, 99, 100]. This cooperation is essential, and while removing WNT-5A from this signaling network may lead to severe embryonic phenotypes, these phenotypes may not be attributed to WNT-5A alone. An intriguing example is the close cooperativity of WNT-5A and WNT-11 in the development of the second heart field in mice. Here, WNT-5A and WNT11 are both required in suppressing $\mathrm{WNT} / \beta$-catenin signaling in progenitors in the developing heart to allow for differentiation [7]. Recently, it was shown that WNT-5A and WNT-11 cooperate to regulate convergent extension movements leading to A-P axis formation in mice [101]. However, mice lacking WNT-5A (and not WNT-11) show severe A-P axis shortening and limb truncations highlighting a redundant role for WNT-11 in this process [5, 101, 102]. Clearly, WNT-5A is an essential component in the machinery that governs embryogenesis, and signaling by WNT-5A is non-redundant with that of other $\beta$-cateninindependent signaling WNTs.

\section{Migration}

Cell migration requires acquisition of new asymmetry and polarity along with reorganization of the cytoskeleton and breaking and/or reprocessing cell-cell and cell-substrate adhesions. As such, the WNT/PCP and WNT/Ca ${ }^{2+}$ pathways have been linked with migration of cells. Several studies have elucidated the significance and molecular mechanisms of WNT-5A-induced cell migration (Fig. 3). For instance, a study has identified the WNT-5A-ROR2 axis in regulating cell motility. WNT-5A interacts with ROR2 and induces its association with Filamin A, an actin binding protein, which, in turn, leads to formation of filopodia [103]. Filopodia are actin-based structures projecting at the leading edge of migrating cells and are important in formation of focal adhesions attaching to the substrate and facilitating directional cell movement [104]. WNT-5A-induced ROR2-Filamin A association activates aPKC which in turn activates JNK. Activated JNK may mediate cell migration by microtubule organizing center (MTOC) reorientation and actin remodeling via phosphorylation and activation of CapZ-interacting protein (CapZIP) [105]. In addition, JNK can also phosphorylate paxillin regulating focal adhesion complexes [106, 107] and modulating cell motility in response to WNT-5A. In another mechanism, WNT-5A induces cell migration via Daple-mediated Rac activation [108]. Daple interacts with DVL in response to WNT-5A and facilitates its interaction with aPKC consequently inducing Rac activation. This leads to cytoskeletal reorganization promoting lamellipodia formation and cell migration [108]. In addition to aPKC, WNT-5A can also employ Rab35 to activate Rac in a DVL-dependent manner and induce cell migration [109].

The WNT-5A-RhoA axis has been prominently linked with cytoskeletal remodeling and cell motility in various cell systems. WNT-5A induces RhoA activation via DVL and Daam1 in breast cancer cells [110] or via PI3K/AKT signaling in gastric cancer cells [57]. Activated RhoA, in turn, may engage other downstream pathways such as JNK to mediate WNT-5A-induced cell migration [67].

CD146, an adhesion molecule, can also activate RhoA and has been shown to be involved in cell migration [74]. Interestingly, WNT-5A induces redistribution of CD146 and accumulation of a unique membrane complex composed of actin, myosin IIB, and $\mathrm{FZD}_{3}$ (termed W-RAMP) asymmetrically at the cell periphery in a DVL- and PKCdependent manner in melanoma cells [75]. This complex, in turn, initiates directional movement and requires RhoBand Rab4-mediated membrane internalization and endosomal trafficking [75]. Of note, the cell movements in this context were RhoA independent. A recent study, on the other hand, has shown that WNT-5A directly binds to CD146 to activate DVL leading to activation of JNK thereby promoting formation of cell protrusions and cell migration [45]. Whether WNT-5A employs RhoA or the membrane complex-W-RAMP, for JNK activation downstream of CD146 is not clear.

Besides non-canonical WNT signaling, WNT-5A can also activate $\beta$-catenin-dependent signaling to promote cell migration. In melanoma cells, WNT-5A activates small GTPase ADP-ribosylation factor 6 (ARF6) via FZD 4 -LRP6 


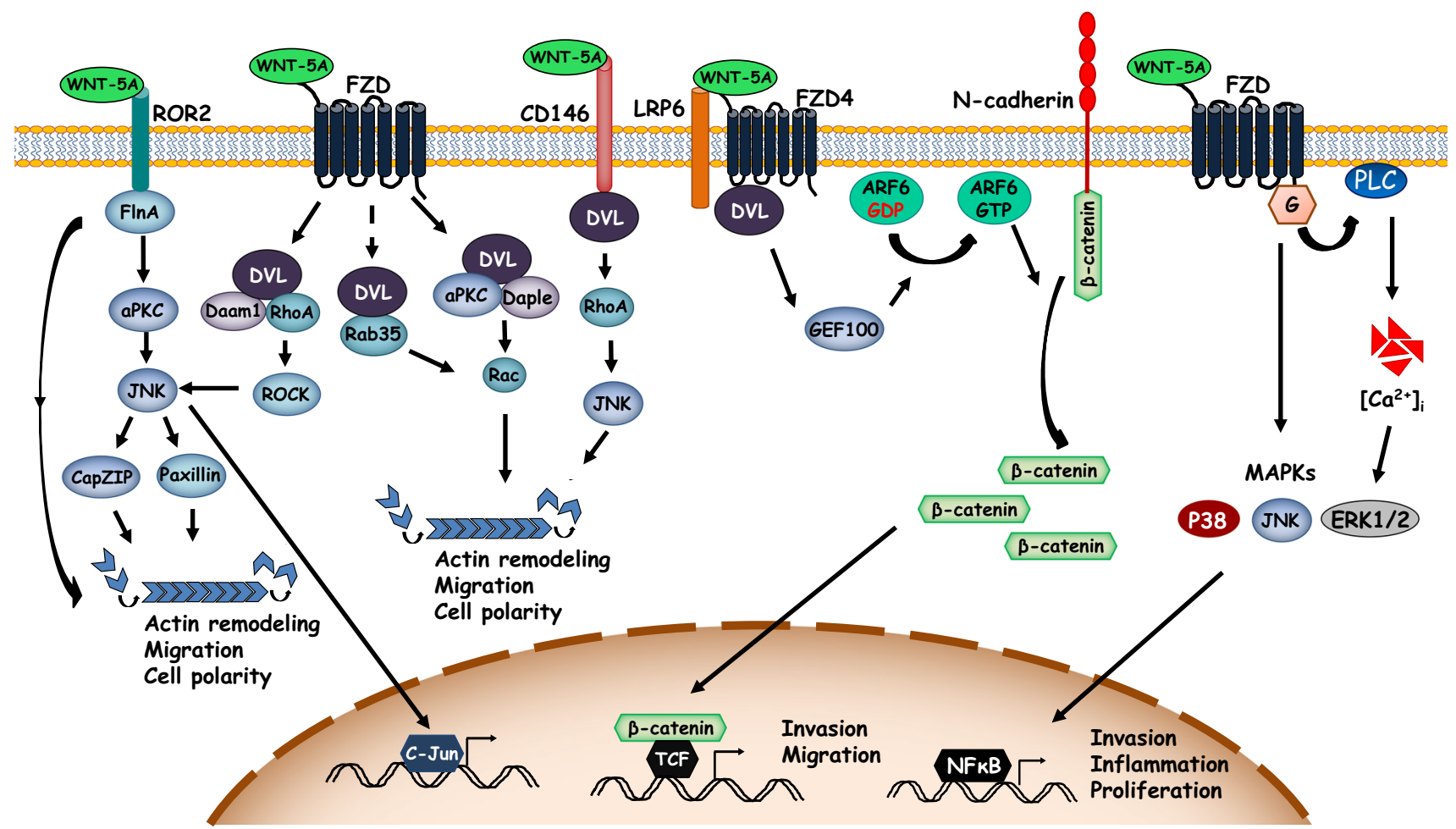

Fig. 3 WNT-5A-activated signaling cascades in cell migration. Diagrammatic representation of few key signaling cascades engaged by WNT-5A to regulate actin cytoskeletal remodeling and cell migration. ARF6 ADP-ribosylation factor 6, GEF100 ARF-guanine nucleotide exchange protein $100, F \ln A$ filamin A, $a P K C$ atypical protein kinase $\mathrm{C}, J N K$ c-Jun $\mathrm{N}$-terminal protein kinase, CapZIP

binding. ARF6 releases membrane-bound $\beta$-catenin from $\mathrm{N}$-cadherin increasing its cytosolic abundance and triggering $\beta$-catenin-dependent transcriptional program that induces invasion and metastasis [46].

WNT-5A can also alter the adhesion properties of cells to regulate migration. For instance, WNT-5A binding to $\mathrm{FZD}_{3}$ activates the PI3K/AKT cascade in human dermal fibroblasts and promotes integrin-mediated adhesion of these cells [41].

Thus, WNT-5A exerts migratory effects in large number of cell and tissue types in physiological and pathological contexts.

\section{Stem cell differentiation and regeneration}

Owing to its property of regulating cell polarity, cell movement, and cell proliferation along with the antagonistic effects on WNT/ $\beta$-catenin signaling, WNT-5A may play a critical role in modulating cell fate determination and differentiation of stem cells.

Hematopoietic stem cells exhibit a shift from $\beta$-catenindependent to -independent WNT signaling with aging where high levels of WNT-5A are present in aged stem cells [10]. Interestingly, treatment of young hematopoietic
CapZ-interacting protein, DVL disheveled, Daam1 DVL-associated activator of morphogenesis 1 , Daple DVL-associating protein with a high frequency of leucine residues, ROCK rho-associated kinase, LRP6 low-density lipoprotein receptor-related protein $6, G \mathrm{G}$ proteins, $\left[\mathrm{Ca}^{2+}\right]_{i}$ intracellular calcium release

stem cells with WNT-5A induces age-related changes such as aging-associated stem cell apolarity, reduced regenerative capacity, and an aging-like myeloid-lymphoid differentiation shift via activation of small Rho GTPase CDC42 [10]. On the other hand, reduction of WNT-5A expression in aged hematopoietic stem cells leads to their functional rejuvenation [10]. Moreover, effects of WNT$5 \mathrm{~A}$ as observed in this study are dependent on the cellintrinsic WNT-5A abundance and not on WNT-5A levels in stromal cells [10]. It is interesting to note that WNT-5A negatively regulates hematopoietic stem cell differentiation via inhibition of $\mathrm{WNT} / \beta$-catenin and NFAT signaling thereby maintaining them in a quiescent stage and promoting their repopulation [73, 111, 112]. This effect is mediated by RYK-dependent inhibition of endogenous reactive oxygen species (ROS) generation [73].

Similarly, WNT-5A is also critical in mesenchymal stem cell (MSC) biology. MSCs can differentiate into multiple cell types such as adipocytes and osteocytes. Higher expression of WNT-5A is detected in MSCs as compared to committed preadipocytes which can only give rise to adipocytes [113]. Interestingly, depletion of WNT$5 \mathrm{~A}$ in MSCs leads to their commitment to adipocytes and loss of osteocyte producing capacity demonstrating that 
WNT-5A is critical for the regulation of differentiation and lineage commitment of MSCs [113]. Indeed, the presence of WNT-5A in human bone marrow MSC inhibits adipogenesis and promotes osteoblastogenesis by inhibition of peroxisome proliferator-activated receptors $\gamma$ (PPAR $\gamma$ ) transactivation via a CaMKII-TAK1-TAK1-binding protein2 (TAB 2)-NLK signaling axis and simultaneous induction of runt-related transcription factor (RUNX) expression [114]. PPAR $\gamma$ activation is required for adipogenesis, whereas RUNX2 is critical for osteogenesis [115]. Interestingly, WNT-5A-activated PKC and ROCK signaling can also induce osteogenic differentiation in adiposetissue-derived mesenchymal stromal cells [116]. Thus, WNT-5A functions as a master regulator determining MSC differentiation into osteogenic or adipogenic lineages.

In line with its role in morphogenesis and stem cell differentiation, WNT-5A has recently been shown to be involved in tissue repair and regeneration after injury. A study demonstrated robust induction of WNT-5A-positive mesenchymal cells following an intestinal injury which are specifically localized in the wound bed [13]. The presence of WNT-5A provided a demarcation of the regenerating proliferative area via potentiation of TGF- $\beta$ signaling. This allowed a fine-tuning of regeneration and proper wound healing [13]. Increased amount of WNT-5A is observed in lung tissue from mouse model of acute respiratory distress syndrome (ARDS) which could be the repair response of damaged lungs to resolve the injury [117]. Indeed, WNT$5 \mathrm{~A}$ can promote the survival of bone marrow derived MSCs following an oxidative-stress injury and can induce their differentiation into the type II alveolar epithelial cells via activation of JNK and PKC signaling [117].

WNT-5A also regulates spermatogenesis by supporting self-renewal and survival of spermatogonial stem cells (SSC) [9]. In contrast to hematopoietic stem cells and MSCs, SSCs do not express WNT-5A but its receptors$\mathrm{FZD}_{3}, \mathrm{FZD}_{5}, \mathrm{FZD}_{7}$, and ROR2. Interestingly, WNT-5A is expressed and provided by the testicular stromal population-sertoli cells, where it promotes SSC maintenance and activity by inhibiting apoptosis in JNK-dependent manner [9].

Thus, WNT-5A may exert a highly context-dependent cell-intrinsic and -extrinsic effects in regulation of stem cell biology, regeneration, and repair.

\section{WNT-5A in disease}

Consistent with the broad functional effects of WNT-5A during embryonic and adult life, disrupted WNT-5A signaling leads to the development of various pathological conditions in humans. We here summarize the role of WNT-5A in human pathologies such as fibrosis, inflammation, and cancer.

\section{Fibrosis}

WNT-5A mRNA and protein expression is increased in fibroblasts obtained from lungs of usual interstitial pneumonia (UIP) patients [16]. Similarly, increased WNT-5A expression is detected in lungs following mechanical ventilation where it participates in the mechanical ventilation-induced pulmonary fibrosis [118]. WNT-5A is also present in high abundance in BAL fluid of sarcoidosis patients [119]. Augmented levels of WNT-5A are also detected in the dermal fibroblasts from keloids [120], whereas WNT-5A expression is identified in the fibrotic areas of affected human liver [121] and found increased in liver tissues from mouse model of liver fibrosis [18, 122].

Activated hepatic stellate cells (HSCs) are keys to the development of fibrotic liver by contributing the extracellular matrix (ECM) and other fibrotic factors. WNT-5A is particularly enriched in the ECM deposited by activated HSCs [121] which express more WNT-5A than the quiescent HSCs [18, 122] and normal human fibroblasts [121].

Fibroblasts from pulmonary fibrosis patients and keloid regions show increased proliferation, survival, and expression of ECM proteins $[123,124]$. WNT-5A engages cAMP-PKA-CREB and PKA-GSK-3 $\beta-\beta$-catenin pathways in dermal fibroblasts protecting them from apoptosis [79]. In line with these observations, WNT-5A promotes proliferation and survival of lung fibroblasts and also augments fibronectin and integrin expression [16]. Similarly, WNT-5A drives proliferation of and ECM deposition by activated HSCs [18]. Tissue fibrosis is an important feature of airway remodeling in obstructive lung diseases such as asthma and chronic obstructive pulmonary disease (COPD) in which airway smooth muscle can play a critical role. We have recently identified a role for WNT-5A in TGF- $\beta$-induced ECM expression in airway smooth muscle cells [21]. WNT-5A is a target of TGF- $\beta$ in airway smooth muscle cells where it engages $\beta$-catenin-independent WNT signaling activating $\mathrm{Ca}^{2+}$-NFAT and JNK to induce ECM expression [21]. While TGF- $\beta$ can regulate WNT-5A expression in airway smooth muscle cells, WNT-5A regulates expression of TGF- $\beta$ in HSCs [18] underlining a critical profibrotic axis in fibrotic disorders.

In contrast of its profibrotic role, WNT-5A may be protective in diabetic renal nephropathy. High-glucose suppresses WNT-5A expression among other WNTs and promotes expression of fibrotic markers via TGF- $\beta$ [125]. Forced expression or presence of recombinant WNT-5A inactivates GSK-3 $\beta$ thereby stabilizing $\beta$ catenin and counteracts high-glucose-induced fibrotic effects [125]. 


\section{Inflammation}

WNT-5A is associated with several inflammatory disorders where it not only mediates proinflammatory cytokine and chemokine production but also regulates migration and recruitment of various immune effector cells.

Microbial pathogens $[42,126]$ and several proinflammatory factors such as IL-1 $\beta$ [31], TNF- $\alpha$ [30], LPS/IFN $\gamma$ [15], and the IL-6 family members LIF and CT-1 [33] induce WNT-5A expression in various cell types highlighting a critical role for WNT-5A in immune responses. Abundant expression of WNT-5A is detected in the granulomatous lesions in the Mycobacterium tuberculosisinfected lungs [42], in the chronic periodontitis tissue [127], sera and bone marrow macrophages of patients with severe sepsis [15], the atherosclerotic lesions in humans and mouse [128], in human dental pulpitis tissues [129], in circulation and visceral fat tissues of obese patients [130], and in the synovial tissue and synovial fibrobalsts from rheumatoid arthritis patients [30, 131].

WNT-5A is associated with the maintenance of innate immune responses both in homeostasis and pathology. Basal WNT-5A expression by macrophages drives static IFN- $\beta$ and $-\gamma$ expression via a Rac1-NFkB pathway and also regulates expression of CD14 which is required for antigen recognition and innate immune responses during infection [132]. In addition, basal WNT-5A signaling also supports survival of macrophages as loss of WNT-5A decreases expression of prosurvival genes such as BCL-2, BCL-xl, and MCL-1, with a concomitant increase in expression of Bax, a proapoptotic protein [132]. Thus, WNT-5A is suggested to contribute to the immune system readiness for countering any future infection. Pathogenic signals such as microbes or microbial products (i.e., LPS) induce expression of WNT-5A which mediates the release of proinflammatory factors such as TNF- $\alpha$, IL- 6 , and interferons from macrophages [132]. In addition, WNT-5A also promotes phagocytosis of microbes in a PI3K-Rac1dependent manner. Interestingly, WNT-5A does not influence bacterial killing inside the phagosome prolonging presence of the antigen and as such might contribute to the development of sepsis by supporting sustenance of the microbial infection and persistence of proinflammatory macrophages at the site of infection [133].

WNT-5A also contributes to the immune responses by regulating the differentiation of $\mathrm{T}$ cells [42]. Mycobacterium infection or the presence of LPS induces WNT-5A expression in human antigen presenting cells and $\mathrm{T}$ cells in a TLR-NFkB-dependent manner where it mediates expression of IL-12 and IFN $\gamma$ [42] contributing to the antimicrobial defense. TLR-4-MyD88 signaling is also associated with downstream effects of WNT-5A to induce expression of IL-12p40 and IL-6 in primary macrophages
[134]. Similarly, LPS/IFN $\gamma$ induces WNT-5A expression in macrophages where it activates CaMKII and mediates the release of IL-1 $\beta$, IL-6, IL-8, and MIP1 $\beta$ [15].

Neutrophil recruitment to the region of infection or site of injury under the influence of various chemoattractants is another key event in innate immune response, whereas excessive neutrophilic inflammation has been linked to various diseases such as asthma and COPD. Human neutrophils express several WNT-5A receptors such as $\mathrm{FZD}_{2}$, $\mathrm{FZD}_{5}$, and $\mathrm{FZD}_{8}$ and treatment with WNT-5A induces the release of IL-8 and CCL2 via MAPK signaling, promoting neutrophil migration [58]. CCL2 is an important neutrophil chemoattractant and is also contributed by the macrophages. WNT-5A upregulates CCL2 expression in macrophages via JNK and NFKB signaling [135] and supernatants from LPS-treated macrophages effectively induce neutrophil migration via WNT-5A [58] emphasizing an important macrophage-neutrophil cross-talk mediated by WNT-5A.

WNT-5A has come under intense scrutiny for its role in neuroinflammatory disorders. WNT-5A induces upregulation of cyclooxygenase-2 (COX-2) expression and production of proinflammatory cytokines IL- $1 \beta$, IL-6, and TNF- $\alpha$ in primary microglia [59]. It has also been associated with the Alzheimer's disease-linked neuroinflammation. $\beta$-Amyloid peptide $(\mathrm{A} \beta)$ induces expression of WNT-5A in primary cortical neurons where it activates $\mathrm{NF \kappa B}$ via upregulation of NF- $\kappa B$-inducing kinase (NIK) and mediates expression of IL-1 $\beta$ [136]. WNT-5A-mediated A $\beta$-induced neuroinflammation is suggested to contribute to the neurotoxicity and Alzheimer's disease-related neural degeneration [136].

The proinflammatory functions of WNT-5A are not only restricted to the immune cells. In human adipocytes, WNT$5 \mathrm{~A}$ induces IL-6 and IL-1 $\beta$ expression [130]. In bone marrow stromal cells, LPS induces WNT-5A where it regulates expression of a plethora of proinflammatory cytokines in a MAPK- and NFKB-dependent signaling and promotes chemotactic migration of monocytes and $\mathrm{T}$ cell indicating a possible role in pathophysiology of rheumatoid arthritis [30]. In endothelial cells, WNT-5A augments COX-2 expression and proinflammatory cytokine production via the $\mathrm{Ca}^{2+}$-PKC-NFKB axis and increases vascular permeability and endothelial cell migration [137]. WNT$5 \mathrm{~A}$ expression is induced in human dental pulp cells following TNF- $\alpha$ stimulation where it regulates IL- 8 and CCL2 expression via a MAPK and NFKB signaling cascade and influences macrophage migration [129].

In contrast to the proinflammatory role, WNT-5A can also have opposing effect on inflammation. It has been shown to negatively regulate LPS-induced inflammatory responses in microglia by inhibiting COX-2 upregulation [138]. Another study showed that WNT-5A could function 
as anti-inflammatory factor by suppressing the proinflammatory M1 phenotype of macrophages in the presence of LPS/IFN $\gamma$ [139] thus limiting the inflammation in various pathological situations. A dose-dependent interaction between WNT-5A and LPS could explain this discrepancy as different doses of LPS elicit differential WNT-5A responses by macrophages. It is quite plausible that low doses of LPS support proinflammatory function of WNT5A, whereas at high LPS doses WNT-5A induces a tolerogenic phenotype in macrophages [133] thereby suppressing inflammation.

\section{Cancer}

WNT/ $\beta$-catenin signaling is closely associated with malignant disorders [140]. WNT-5A, owing to its properties of both activating and inhibiting WNT/ $\beta$-catenin signaling and regulating cell movements, can be linked with cancer pathobiology. Studies have proposed both proand anti-tumor functions for WNT-5A and have identified several underlying signaling cascades (Table 1). Low or loss of expression of WNT-5A is linked to increased metastatic and invasive phenotype and poor prognosis in breast and colorectal cancers, whereas in thyroid cancer, it may have tumor-suppressor activity despite its increased expression [141-144]. Likewise, deletion or loss of WNT$5 \mathrm{~A}$ expression is observed in human $\mathrm{B}$ cell lymphomas and myeloid leukemias [145]. On the other hand, strong expression of WNT-5A is shown in prostate cancer, acute T-cell leukemia, melanomas, and non-melanomas where it correlates with cell motility and tumor invasiveness [146151].

Aberrant expression of components of $\beta$-catenin-independent pathway, WNT/PCP, has also been reported in Chronic lymphocytic leukemia (CLL) [152]. The study showed that WNT-5A, which is also expressed in the CLL cells, promotes polarized cell migration towards chemokine gradient (CXCL10, CXCL11, CXCL12, and CCL21) in CK1-dependent manner [152]. In another example, high expression of WNT-5A is observed in the PBMCs derived from acute T-cell leukemia/lymphoma (ATL) patients [151]. Due to its effects on osteoclast differentiation [151], WNT-5A may drive osteolytic bone lesions and hypercalcemia which are the major complications in ATL patients [153, 154].

In contrast to CLL and ATL, WNT-5A may have tumor suppressive effects in ALL. Loss of WNT-5A expression is reported in acute myeloid and acute lymphoblast leukemia [145]. WNT-5A has been shown to be epigenetically silenced by promoter hypermethylation in acute lymphoblast leukemia cells leading to the loss of expression which may drive unrestricted B cell proliferation and malignant development [155]. Indeed, WNT-5A heterozygous mice develop spontaneous B cell malignancies underlining the tumor suppressive role of WNT-5A [145].

Similarly, WNT-5A promoter hypermethylation is also observed in the esophageal squamous cell carcinoma (ESCC) tissues [156]. Ectopic expression of WNT-5A led to reduction in $\beta$-catenin signaling and inhibition of clonogenicity and motility in ESCC cell lines suggesting the tumor suppressive role of WNT-5A in ESCC [156].

WNT-5A expression is highly increased in gastric cancer and positively associates with tumor invasiveness, metastasis, and survival of the patients [157]. Administration of anti-WNT-5A antibody attenuates liver metastases of gastric cancer cells in vivo [158]. WNT-5A employs several mechanisms to regulate gastric cell invasiveness such as activation of focal adhesion kinase and Rac1 to regulate turnover of paxillin-containing adhesions [157], activation of PI3K/AKT pathway to regulate actin stress fiber formation [57], and activation of JNK and PKC signaling to induce Laminin $\gamma 2$ [159] promoting cell migration. Additionally, WNT-5A abundance correlates with the expression of MCP-1 and IL- $1 \beta$ in gastric cancer tissues indicating that WNT-5A may drive macrophage infiltration and tumor-related inflammation [160].

WNT-5A expression is highly increased in non-small cell lung cancer (NSCLC) and has been associated with poor prognosis $[161,162]$. Tobacco smoke is a very potent inducer of lung cancer [163] and exposure to cigarette smoke-extract induces WNT-5A expression in human bronchial epithelial cells [164]. WNT-5A activates PKC to upregulate anti-apoptotic genes such as BCL-2 in these cells thereby protecting them from death explaining the tumorigenic properties of WNT-5A [164].

Extensive WNT-5A expression is detected in human melanoma biopsies where it correlates with the formation of distant metastases and poor prognosis $[148,150]$. WNT$5 \mathrm{~A}$ strongly induces cell migration and invasion of melanoma cells, possibly, by inducing epithelial-tomesenchymal transition (EMT) while decreasing the expression of metastatic suppressors [150, 165]. IL-6 induces WNT-5A in melanoma cells via p38 which, in turn, mediates cell migration [166]. As discussed earlier, WNT-5A activates ARF6 in melanoma cells leading to disruption of $\mathrm{N}$-cadherin- $\beta$-catenin interaction, enhanced $\beta$-catenin-mediated transcription and invasion [46]. It can also activate $\mathrm{Ca}^{2+}$-dependent signaling leading to the activation of calpain protease which cleaves filamin A. Cleavage of filamin A induces cytoskeletal remodeling and cell motility [167]. WNT-5A can also confer a survival advantage to melanoma cells, thereby negatively influencing the outcome of therapeutic approaches. Prolonged treatment with BRAF inhibitors induces WNT-5A expression in melanoma cells and contributes to the development of resistance to BRAF inhibitor-induced 
Table 1 WNT-5A in cancer

\begin{tabular}{|c|c|c|c|c|}
\hline Cancer & Expression & Signaling & Effector(s) & Consequence(s) \\
\hline Prostate & Upregulated $[146,147,168]$ & $\begin{array}{l}\text { PKD-JNK-JunD [147] } \\
\text { PKC-NFKB [171] } \\
\mathrm{Ca}^{2+}-\mathrm{CaMKII} \mathrm{[146]}\end{array}$ & $\begin{array}{l}\text { MMP1 [147, 169] } \\
\text { BMP6 [171] }\end{array}$ & $\begin{array}{l}\text { Invasion, metastasis [146, 147, 169] } \\
\text { Proliferation [171] }\end{array}$ \\
\hline Non-melanoma & Upregulated [149] & $?$ & $?$ & Invasion [149] \\
\hline Melanoma & Upregulated $[48,148,150]$ & $\begin{array}{l}\text { GEP100-ARF6 [46] } \\
\mathrm{Ca}^{2+} \text {-Calpain [167] } \\
\text { AKT [48] } \\
\mathrm{Ca}^{2+} \text {, CDC42 [172] } \\
\text { PKC-STAT3 [173] }\end{array}$ & $\begin{array}{l}\beta \text {-Catenin [46] } \\
\text { Filamin A [167] } \\
\text { VEGF, IL-6, MMP2 [172] } \\
\text { LDH5 [174] }\end{array}$ & $\begin{array}{l}\text { Invasion, migration }[46,150,166,167] \\
\text { EMT [165] } \\
\text { Survival, proliferation [48] } \\
\text { Angiogenesis [172] } \\
\text { Immune evasion [173] } \\
\text { Metabolic reprogramming [174] }\end{array}$ \\
\hline Gastric & Upregulated [157] & $\begin{array}{l}\text { FAK, Rac1 [157] } \\
\text { PI3K-AKT [57] } \\
\text { JNK, PKC [159] }\end{array}$ & $\begin{array}{l}\text { Paxillin [157] } \\
\text { Actin [57] } \\
\text { Laminin } \gamma 2 \text { [159] }\end{array}$ & $\begin{array}{l}\text { Migration [57, 157-159] } \\
\text { Tumor inflammation [160] }\end{array}$ \\
\hline NSCLC & Upregulated $[161,162]$ & PKC-AKT [164] & BCL-2 [164] & Survival [164] \\
\hline Acute ATL & Upregulated [151] & $?$ & RANK [151] & Osteolytic lesions [151] \\
\hline Colorectal $^{\mathrm{a}}$ & Upregulated [184] & $?$ & $?$ & Invasion [184] \\
\hline Thyroid $^{c}$ & Upregulated $[143]^{\mathrm{c}}$ & $\mathrm{Ca}^{2+}-\mathrm{CaMKII}[143]$ & $\beta$-Catenin $[143]^{\mathrm{c}}$ & (Reduced) proliferation, migration $[143]^{\mathrm{c}}$ \\
\hline Breast & Downregulated $[141,142]$ & CDC42 [189] & $\begin{array}{l}\beta \text {-Catenin }[188] \\
\text { MMP9 [189] }\end{array}$ & $\begin{array}{l}\text { Tumor growth [185] } \\
\text { Invasion [187-189] }\end{array}$ \\
\hline Colorectal $^{\mathrm{b}}$ & Downregulated [144] & $?$ & $\beta$-Catenin [179] & Proliferation, migration $[144,179,183]$ \\
\hline AML/ALL & Downregulated [145] & $?$ & $?$ & B cell proliferation [145] \\
\hline ESCC & Downregulated [156] & $?$ & $\beta$-Catenin [156] & Proliferation, migration [156] \\
\hline
\end{tabular}

? unknown

a Early recurrence or metastatic

b Lymph-node negative or Dukes' B

${ }^{c}$ Despite overexpression, WNT-5A is suggested to function as tumor suppressor in thyroid carcinoma, reduces $\beta$-catenin activity and proliferation and migration

apoptosis [48]. This process involves $\mathrm{FZD}_{7^{-}}$and $\mathrm{RYK}$ mediated activation of prosurvival AKT signaling [48]. Knock-down of endogenous WNT-5A decreases melanoma cell proliferation and sensitizes them to BRAF inhibitor-induced cell death [48].

WNT-5A regulates motility in prostate cancer cells as well by promoting actin remodeling via $\mathrm{Ca}^{2+}-\mathrm{CaMKII}$ signaling [146]. Prostate cancer tissues show increased expression of WNT-5A [146, 168] promoting migration and invasiveness [147]. WNT-5A signaling through ROR2 and $\mathrm{FZD}_{2}$ activates protein kinase $\mathrm{D}$ (PKD) and JNK to induce Matrixmetalloprotease 1 (MMP1) expression via JunD [147]. MMP1 expression is important for prostate cancer cell invasiveness and bone metastasis [169]. Bone is a major site for metastasis of various tumors including prostate cancer. Prostate cancer cells show increased migration towards bone marrow stromal cells which is suppressed in the presence of WNT-5A siRNA-transfected bone marrow stromal cells, suggesting that WNT-5A can also function as a chemoattractant or homing factor for prostate cancer cells [170]. The prostate cancer and bone cross-talk also promotes prostate cancer cell proliferation. WNT-5A expressed by bone marrow stromal cells induces expression of BMP-6 in prostate cancer cells via a PKCNFкB pathway [171]. BMP-6, in turn, activates SMAD and $\beta$-catenin signaling to promote proliferation in prostate cancer cells [171]. Indeed, considerable nuclear $\beta$-catenin staining is found in prostate cancer tissues [147]. This signaling mechanism also explains the development of castration-resistant prostate cancer phenotype. Prostate cancer cells require androgens for their growth and as such androgen restriction is first-line therapy for prostate cancer patients. With time, considerable subsets of patients develop androgen-resistant prostate cancer. WNT-5A induced BMP-6, thus contributes to the proliferation of prostate cancer cells in the absence of androgens [171].

Studies have suggested a broader function for WNT-5A in cancer than just cell growth and invasion. For instance, it can relay immunomodulatory and proangiogenic functions or modulate cell survival. WNT-5A induces the release of IL-6, MMP2, and vascular endothelial growth factor (VEGF) containing exosomes from melanoma cells in a 
$\mathrm{Ca}^{2+}$ - and $\mathrm{CDC} 42$-dependent process that requires cytoskeletal reorganization [172]. Co-culture of WNT-5Adeficient melanoma cells with endothelial cells suppresses endothelial cell branching, whereas treatment of endothelial cells with exosomes isolated from WNT-5A-treated melanoma cells induces angiogenesis highlighting a proangiogenic role for WNT-5A [172]. WNT-5A also suppresses expression of tumor-associated antigens in melanoma cells via activation of PKC and STAT3. This leads to impaired cytotoxic T-cell clearance of tumor cells [173]. Interestingly, WNT-5A can drive metabolic reprogramming in cancer cells by inducing lactate dehydrogenase 5 (LDH5) leading to an increase in anaerobic glycolysis [174]. The serum level of LDH is an important predictor of prognosis and treatment response in melanoma patients [175]. WNT-5A and LDH5 expression levels positively correlate in melanoma patient tissue samples [174]. This is particularly important as strong staining of both WNT5A and LDH5 is linked with reduced disease-free survival in melanoma patients [148, 174]. Contrary to its effects in melanoma cells, WNT-5A increases oxidative phosphorylation rates in breast cancer cells demonstrating a context-dependent function of WNT$5 \mathrm{~A}$ that can also explain its tumor-promoter and tumorsuppressor roles [174].

What drives increased expression of WNT-5A in cancer cells? A study has found that microRNA-26a expression is reduced in prostate cancer cells [176]. miR-26a suppresses WNT-5A and forced expression of miR-26a attenuates cell proliferation, metastasis, and EMT, and induced G1 phase arrest suppressing WNT-5A expression and inhibiting prostate cancer progression [176]. Epigenetic mechanisms could also participate in the aberrant expression of WNT$5 \mathrm{~A}$ in cancer cells. Hypomethylation of the WNT-5A promoter in prostate cancer cells accounts for the increased transcription of WNT-5A in these cells [177]. In another scenario, reduced expression of WNT-5A antagonists such as Klotho might contribute to increased availability and signaling of WNT-5A in cancer cells [178]. Expressions of Klotho and WNT-5A are inversely correlated in melanoma tissues, whereas the presence of Klotho suppressed melanoma cell invasion [178].

In addition to tumor-promoting activity, WNT-5A also functions as tumor suppressor in few cancer types. In colorectal cancer (CRC), loss of WNT-5A is frequently observed and associated with poor prognosis and survival [144]. In line with this, methylation of the WNT-5A promoter is observed in metastatic CRC cell lines explaining low abundance of WNT-5A in CRC $[179,180]$. Promoter methylation of WNT-5A is associated with distinct tumor subtypes in colorectal cancer [181, 182]. Treatment of CRC cells with Genistein, a soy flavonone and tyrosine kinase inhibitor with protective activity in CRC, reduces
WNT-5A promoter methylation thereby increasing WNT5A gene expression and inhibiting cell proliferation [183]. WNT-5A also attenuates migration of colon cancer cell lines [144]. As activated WNT/ $\beta$-catenin is associated with CRC, ectopic expression of WNT5A resulted in substantial inhibition of tumor cell clonogenicity of CRC cells, with downregulation of intracellular $\beta$-catenin protein level and concomitant decrease in $\beta$-catenin activity [179].

In a contrasting study, increased WNT-5A expression is associated with poor prognosis in CRC patients and WNT$5 \mathrm{~A}$ promoted directional cell migration and invasion in CRC cells. However, increased expression of WNT-5A is not sufficient to augment malignancy or metastasis in APCdriven intestinal tumor model [184] suggesting that additional, not yet understood, mechanisms govern WNT-5A activity at different stages of cancer pathogenesis. While further studies are required to elucidate a clear role of WNT-5A in CRC, it is tempting to speculate that WNT-5A acts as a tumor suppressor in $\beta$-catenin-dependent stages of CRC progression.

Loss of WNT-5A is observed in primary invasive breast cancers and is associated with higher histological grade and rapid appearance of distant metastases leading to shorter recurrence-free survival in these patients $[141,142]$. The low abundance of WNT-5A in breast cancer cells could be attributed to epigenetic silencing of the WNT-5A promoter. Elevated expression of protein inhibitor of activated STAT 1 (PIAS1) is found in breast cancer tissues and it has been shown to associate with methylated regions of WNT-5A promoter in breast cancer cells [185]. PIAS1, a transcriptional regulator, is known to recruit DNA methyltransferases (DNMTs) thereby regulating promoter methylation. Of note, knock-down of PIAS1 coincides with reduced methylation and increased acetylation of the WNT-5A promoter indicating gene activation with a subsequent increase in WNT-5A expression. It leads to reduction in the number of tumor-initiating cells and attenuates breast cancer growth in vivo suggesting that epigenetic silencing of WNT-5A via PIAS1 is an important feature in breast cancer [185]. Additionally, the low WNT5A expression could also be due to posttranslational suppression of WNT-5A mRNA in breast cancer cells by HuR proteins. Of note, HuR expression is highly augmented in invasive breast cancer cells [36]. Further, miRNA-374a is highly increased in breast cancer tissues and is associated with poor metastasis-free survival [186]. miRNA-374a promotes EMT and metastasis in breast cancer cells both in vivo and in vitro via targeted downregulation of negative regulators of $\mathrm{WNT} / \beta$-catenin signaling such as WNT-5A [186].

The tumor suppressive function could also be attributed to adhesion promoting function of WNT-5A in certain cell types. WNT-5A could regulate mammary epithelial cell 
adhesion by phosphorylating Discoidin domain receptor 1 and activating its interaction with collagen thereby negatively regulating cell migration [187]. Similarly, WNT-5A stimulation of breast epithelial cells increases adhesion by inducing $\mathrm{CK} 1 \alpha$-dependent phosphorylation of $\beta$-catenin which, in turn, promotes E-cadherin- $\beta$-catenin association [188]. This stabilizes adheres junctions and attenuates $\beta$ catenin transcriptional function [188]. WNT-5A activates CDC42 in various cell types including breast cancer cells. A study found that WNT-5A-activated CDC42 limits ERK1/2 activation and subsequent MMP9 expression. This is suggested to restrain cell migration and invasiveness in breast cancer [189]. In agreement with these observations, small WNT-5A-derived peptides could increase adhesion and decrease metastasis and invasion of breast cancer cells both in vitro and in vivo $[190,191]$.

In contrast to the tumor-suppressor function of WNT-5A in breast cancer, studies have also suggested a cell migration-promoting role for WNT-5A. In a breast cancer cell line MDA-MB-231 which expresses very low endogenous WNT-5A, stimulation with WNT-5A activated a DVL2- and Daam1-dependent RhoA signaling inducing cell migration [110], whereas in another breast cancer cell line with high endogenous WNT-5A levels (MCF-7), WNT-5A can promote cell migration via a DVL2-Rab35-Rac1-dependent and RhoA-independent signaling [109]. In a contrasting study using MCF-7 cell line, WNT-5A attenuated filopodia formation and cell migration via activation of cAMP-regulated phosphoprotein of $32 \mathrm{kDa}$ (DARPP-32) and CREB [192]. Interestingly, macrophages associated with primary breast cancer tissues have been shown to express WNT-5A [193]. The co-culture of MCF-7 with macrophages promotes WNT-5A expression in macrophages and invasiveness of MCF-7, a feature which was also recapitulated by direct stimulation of MCF-7 with recombinant WNT-5A [193]. Similarly, microglia, the resident brain macrophages, have been shown to enhance breast cancer cell (MCF-7) invasion in a WNT-dependent manner [194]. The study showed microglia transporting breast cancer cells into the brain tissue [194]. Of note, WNT-5A has been shown to induce proliferation and invasion of microglia [59]. While the procell migratory effects of WNT-5A in breast cancer require further studies, it is quite possible that WNT-5A regulates breast cancer metastasis depending on the tumor-microenvironment communication.

The opposing roles for WNT-5A in cancer are intriguing and are matter of intense investigation. As WNT-5A antagonizes WNT/ $\beta$-catenin signaling, it is tempting to speculate that it functions as tumor suppressor in $\mathrm{WNT} / \beta$ catenin-dependent cancers provided it activates the downstream cascade involved in this antagonism. The pro-tumor activity might be attributed to the cell migratory, proliferative. and prosurvival effects of WNT-5A. Moreover, the differential role of WNT-5A could also be due to different properties of recently characterized WNT-5A isoforms. WNT-5A promoter generates two identical transcripts utilizing alternative transcription start sites-WNT-5A-L and WNT-5A-S [24-26]. While WNT-5AL inhibits tumor growth, WNT-5AS promotes it. Expression of these two isoforms is altered in breast cancer, cervix carcinoma, and aggressive neuroblastomas where WNT-5A-L is downregulated and WNT-5A-S is most abundantly expressed [25]. Thus, not only the downstream signaling but also the abundance of specific isoforms can contribute to the differential effects of WNT-5A in cancer. Thus, the downstream effects of WNT-5A are highly context dependent and the differential signaling mechanisms it engages may account for the opposing functions of WNT$5 \mathrm{~A}$ in cancer.

\section{WNT-5A as a therapeutic target}

While we still await a clear understanding of WNT-5A biology, development of certain WNT-5A mimicking molecules and their beneficial effects in animal models of diseases raise hopes for therapeutic targeting of WNT-5A for curing deadly diseases. Foxy5 is a WNT5A derived $\mathrm{N}$-formylated hexapeptide which mimics tumor suppressive effects of WNT5A on breast cancer both in vitro [190, 191] and in vivo [191]. The presence of Foxy5 has antimigratory effects on breast cancer cell line $[190,191]$ and administration of Foxy5 has been shown to prevent lung and liver metastases in a mouse model of breast cancer [191]. The substitution of N-terminal formyl group of Foxy5 with a t-butoxycarbonyl group (t-boc) reversed its function turning Foxy5 into WNT-5A antagonist, termed Box5 [195]. Box5 antagonizes WNT-5A-induced melanoma cell invasion [195] and prevents $\beta$-amyloid peptideinduced WNT-5A-dependent inflammation and neurotoxicity in mouse cortical cultures [136].

Likewise, UM206, a oligopeptide with high homology to WNT-5A, functions as a $\mathrm{FZD}_{1} / \mathrm{FZD}_{2}$ antagonist with therapeutic benefit in reducing cardiac remodeling an animal model of myocardial infarction [196]. Although the effects of UM206 cannot be attributed specifically to WNT-5A as the peptide also blocks signaling induced by WNT-3A, WNT-5A is known to regulate fibroblast proliferation, migration, and activation leading to matrix remodeling $[16,103]$.

\section{Conclusion}

WNT-5A is a pleotropic growth factor with wide-ranging effects in different cells and tissues, regulating key functions throughout the human life span. While it is 
indispensable for proper embryonic development, it is equally critical for maintenance of tissue homeostasis in adult life. Simultaneously, derailed WNT-5A signaling results in various pathological disorders in humans. Understanding the mechanisms involved in the maintenance of WNT-5A homeostasis such as its inducers and signaling partners, both positive and negative modulators, is key for therapeutic targeting of this important WNT in various diseases.

Acknowledgments The authors of this work were supported by a Vidi grant (016.126.307) from the Dutch Organization for Scientific Research (NWO).

\section{Compliance with ethical standards}

Conflict of interest The authors have no other relevant affiliations or financial involvement with any organization or entity with a financial interest in or financial conflict with the subject matter or materials discussed in the manuscript apart from those disclosed.

Open Access This article is distributed under the terms of the Creative Commons Attribution 4.0 International License (http:// creativecommons.org/licenses/by/4.0/), which permits unrestricted use, distribution, and reproduction in any medium, provided you give appropriate credit to the original author(s) and the source, provide a link to the Creative Commons license, and indicate if changes were made.

\section{References}

1. Baarsma HA, Konigshoff M, Gosens R (2013) The WNT signaling pathway from ligand secretion to gene transcription: molecular mechanisms and pharmacological targets. Pharmacol Ther 138:66-83

2. McNeill H, Woodgett JR (2010) When pathways collide: collaboration and connivance among signalling proteins in development. Nat Rev Mol Cell Biol 11:404-413

3. Ishitani T, Kishida S, Hyodo-Miura J, Ueno N, Yasuda J, Waterman M, Shibuya H, Moon RT, Ninomiya-Tsuji J, Matsumoto K (2003) The TAK1-NLK mitogen-activated protein kinase cascade functions in the Wnt- $5 \mathrm{a} / \mathrm{Ca}(2+)$ pathway to antagonize Wnt/beta-catenin signaling. Mol Cell Biol 23:131139

4. Nishita M, Enomoto M, Yamagata K, Minami Y (2010) Cell/ tissue-tropic functions of Wnt5a signaling in normal and cancer cells. Trends Cell Biol 20:346-354

5. Yamaguchi TP, Bradley A, McMahon AP, Jones S (1999) A Wnt5a pathway underlies outgrowth of multiple structures in the vertebrate embryo. Development 126:1211-1223

6. Li C, Xiao J, Hormi K, Borok Z, Minoo P (2002) Wnt5a participates in distal lung morphogenesis. Dev Biol 248:68-81

7. Cohen ED, Miller MF, Wang Z, Moon RT, Morrisey EE (2012) Wnt5a and Wnt11 are essential for second heart field progenitor development. Development 139:1931-1940

8. Roarty K, Serra R (2007) Wnt5a is required for proper mammary gland development and TGF-beta-mediated inhibition of ductal growth. Development 134:3929-3939

9. Yeh JR, Zhang X, Nagano MC (2011) Wnt5a is a cell-extrinsic factor that supports self-renewal of mouse spermatogonial stem cells. J Cell Sci 124:2357-2366
10. Florian MC, Nattamai KJ, Dorr K, Marka G, Uberle B, Vas V, Eckl C, Andra I, Schiemann M, Oostendorp RA, ScharffetterKochanek K, Kestler HA, Zheng Y, Geiger H (2013) A canonical to non-canonical Wnt signalling switch in haematopoietic stem-cell ageing. Nature 503:392-396

11. Maeda K, Kobayashi Y, Udagawa N, Uehara S, Ishihara A, Mizoguchi T, Kikuchi Y, Takada I, Kato S, Kani S, Nishita M, Marumo K, Martin TJ, Minami Y, Takahashi N (2012) Wnt5aRor2 signaling between osteoblast-lineage cells and osteoclast precursors enhances osteoclastogenesis. Nat Med 18:405-412

12. Nemoto E, Ebe Y, Kanaya S, Tsuchiya M, Nakamura T, Tamura M, Shimauchi H (2012) Wnt5a signaling is a substantial constituent in bone morphogenetic protein-2-mediated osteoblastogenesis. Biochem Biophys Res Commun 422:627632

13. Miyoshi H, Ajima R, Luo CT, Yamaguchi TP, Stappenbeck TS (2012) Wnt5a potentiates TGF-beta signaling to promote colonic crypt regeneration after tissue injury. Science 338:108-113

14. Iozzo RV, Eichstetter I, Danielson KG (1995) Aberrant expression of the growth factor Wnt-5A in human malignancy. Cancer Res 55:3495-3499

15. Pereira C, Schaer DJ, Bachli EB, Kurrer MO, Schoedon G (2008) Wnt5A/CaMKII signaling contributes to the inflammatory response of macrophages and is a target for the antiinflammatory action of activated protein $\mathrm{C}$ and interleukin10. Arterioscler Thromb Vasc Biol 28:504-510

16. Vuga LJ, Ben-Yehudah A, Kovkarova-Naumovski E, Oriss T, Gibson KF, Feghali-Bostwick C, Kaminski N (2009) WNT5A is a regulator of fibroblast proliferation and resistance to apoptosis. Am J Respir Cell Mol Biol 41:583-589

17. Li X, Yamagata K, Nishita M, Endo M, Arfian N, Rikitake Y, Emoto N, Hirata K, Tanaka Y, Minami Y (2013) Activation of Wnt5a-Ror2 signaling associated with epithelial-to-mesenchymal transition of tubular epithelial cells during renal fibrosis. Genes Cells 18:608-619

18. Xiong WJ, Hu LJ, Jian YC, Wang LJ, Jiang M, Li W, He Y (2012) Wnt5a participates in hepatic stellate cell activation observed by gene expression profile and functional assays. World J Gastroenterol 18:1745-1752

19. Lee KH, Johmura Y, Yu LR, Park JE, Gao Y, Bang JK, Zhou M, Veenstra TD, Yeon Kim B, Lee KS (2012) Identification of a novel Wnt5a-CK1varepsilon-Dvl2-Plk1-mediated primary cilia disassembly pathway. EMBO J 31:3104-3117

20. Woldt E, Terrand J, Mlih M, Matz RL, Bruban V, Coudane F, Foppolo S, El Asmar Z, Chollet ME, Ninio E, Bednarczyk A, Thierse D, Schaeffer C, Van Dorsselaer A, Boudier C, Wahli W, Chambon P, Metzger D, Herz J, Boucher P (2012) The nuclear hormone receptor PPARgamma counteracts vascular calcification by inhibiting Wnt5a signalling in vascular smooth muscle cells. Nat Commun 3:1077

21. Kumawat K, Menzen MH, Bos IS, Baarsma HA, Borger P, Roth M, Tamm M, Halayko AJ, Simoons M, Prins A, Postma DS, Schmidt M, Gosens R (2013) Noncanonical WNT-5A signaling regulates TGF-beta-induced extracellular matrix production by airway smooth muscle cells. FASEB J 27:1631-1643

22. Gavin BJ, McMahon JA, McMahon AP (1990) Expression of multiple novel Wnt-1/int-1-related genes during fetal and adult mouse development. Genes Dev 4:2319-2332

23. Clark CC, Cohen I, Eichstetter I, Cannizzaro LA, McPherson JD, Wasmuth JJ, Iozzo RV (1993) Molecular cloning of the human proto-oncogene Wnt-5A and mapping of the gene (WNT5A) to chromosome 3p14-p21. Genomics 18:249-260

24. Katoh M, Katoh M (2009) Transcriptional mechanisms of WNT5A based on NF-kappaB, Hedgehog, TGFbeta, and Notch signaling cascades. Int J Mol Med 23:763-769 
25. Bauer M, Benard J, Gaasterland T, Willert K, Cappellen D (2013) WNT5A encodes two isoforms with distinct functions in cancers. PLoS One 8:e80526

26. Katula KS, Joyner-Powell NB, Hsu CC, Kuk A (2012) Differential regulation of the mouse and human Wnt5a alternative promoters A and B. DNA Cell Biol 31:1585-1597

27. Ripka S, Konig A, Buchholz M, Wagner M, Sipos B, Kloppel G, Downward J, Gress T, Michl P (2007) WNT5A-target of CUTL1 and potent modulator of tumor cell migration and invasion in pancreatic cancer. Carcinogenesis 28:1178-1187

28. Katoh M, Katoh M (2007) STAT3-induced WNT5A signaling loop in embryonic stem cells, adult normal tissues, chronic persistent inflammation, rheumatoid arthritis and cancer (review). Int J Mol Med 19:273-278

29. Chen L, Fulcoli FG, Ferrentino R, Martucciello S, Illingworth EA, Baldini A (2012) Transcriptional control in cardiac progenitors: Tbx1 interacts with the BAF chromatin remodeling complex and regulates Wnt5a. PLoS Genet 8:e1002571

30. Rauner M, Stein N, Winzer M, Goettsch C, Zwerina J, Schett G, Distler JH, Albers J, Schulze J, Schinke T, Bornhauser M, Platzbecker U, Hofbauer LC (2012) WNT5A is induced by inflammatory mediators in bone marrow stromal cells and regulates cytokine and chemokine production. J Bone Miner Res 27:575-585

31. Ge XP, Gan YH, Zhang CG, Zhou CY, Ma KT, Meng JH, Ma XC (2011) Requirement of the NF-kappaB pathway for induction of Wnt-5A by interleukin-1beta in condylar chondrocytes of the temporomandibular joint: functional crosstalk between the Wnt-5A and NF-kappaB signaling pathways. Osteoarthritis Cartilage 19:111-117

32. Kumawat K, Menzen MH, Slegtenhorst RM, Halayko AJ, Schmidt M, Gosens R (2014) TGF-beta-activated kinase 1 (TAK1) signaling regulates TGF-beta-induced WNT-5A expression in airway smooth muscle cells via $\mathrm{Sp} 1$ and betacatenin. PLoS One 9:e94801

33. Fujio Y, Matsuda T, Oshima Y, Maeda M, Mohri T, Ito T, Takatani T, Hirata M, Nakaoka Y, Kimura R, Kishimoto T, Azuma J (2004) Signals through gp130 upregulate Wnt5a and contribute to cell adhesion in cardiac myocytes. FEBS Lett 573:202-206

34. MacLeod RJ, Hayes M, Pacheco I (2007) Wnt5a secretion stimulated by the extracellular calcium-sensing receptor inhibits defective Wnt signaling in colon cancer cells. Am J Physiol Gastrointest Liver Physiol 293:G403-G411

35. Wang Z, Chen H (2009) Amino acid limitation induces downregulation of WNT5a at transcriptional level. Biochem Biophys Res Commun 378:789-794

36. Leandersson K, Riesbeck K, Andersson T (2006) Wnt-5a mRNA translation is suppressed by the Elav-like protein HuR in human breast epithelial cells. Nucleic Acids Res 34:3988-3999

37. Mikels AJ, Nusse R (2006) Purified Wnt5a protein activates or inhibits beta-catenin-TCF signaling depending on receptor context. PLoS Biol 4:e115

38. Kurayoshi M, Yamamoto H, Izumi S, Kikuchi A (2007) Posttranslational palmitoylation and glycosylation of Wnt-5a are necessary for its signalling. Biochem J 402:515-523

39. Schulte G, Bryja V, Rawal N, Castelo-Branco G, Sousa KM, Arenas E (2005) Purified Wnt-5a increases differentiation of midbrain dopaminergic cells and dishevelled phosphorylation. J Neurochem 92:1550-1553

40. Sato A, Yamamoto H, Sakane H, Koyama H, Kikuchi A (2010) Wnt5a regulates distinct signalling pathways by binding to Frizzled2. EMBO J 29:41-54

41. Kawasaki A, Torii K, Yamashita Y, Nishizawa K, Kanekura K, Katada M, Ito M, Nishimoto I, Terashita K, Aiso S, Matsuoka M (2007) Wnt5a promotes adhesion of human dermal fibroblasts by triggering a phosphatidylinositol-3 kinase/Akt signal. Cell Signal 19:2498-2506

42. Blumenthal A, Ehlers S, Lauber J, Buer J, Lange C, Goldmann T, Heine H, Brandt E, Reiling N (2006) The Wingless homolog WNT5A and its receptor Frizzled-5 regulate inflammatory responses of human mononuclear cells induced by microbial stimulation. Blood 108:965-973

43. Keeble TR, Halford MM, Seaman C, Kee N, Macheda M, Anderson RB, Stacker SA, Cooper HM (2006) The Wnt receptor Ryk is required for Wnt5a-mediated axon guidance on the contralateral side of the corpus callosum. J Neurosci 26:5840-5848

44. Oishi I, Suzuki H, Onishi N, Takada R, Kani S, Ohkawara B, Koshida I, Suzuki K, Yamada G, Schwabe GC, Mundlos S, Shibuya H, Takada S, Minami Y (2003) The receptor tyrosine kinase Ror2 is involved in non-canonical Wnt5a/JNK signalling pathway. Genes Cells 8:645-654

45. Ye Z, Zhang C, Tu T, Sun M, Liu D, Lu D, Feng J, Yang D, Liu F, Yan X (2013) Wnt5a uses CD146 as a receptor to regulate cell motility and convergent extension. Nat Commun 4:2803

46. Grossmann AH, Yoo JH, Clancy J, Sorensen LK, Sedgwick A, Tong Z, Ostanin K, Rogers A, Grossmann KF, Tripp SR, Thomas KR, D'Souza-Schorey C, Odelberg SJ, Li DY (2013) The small GTPase ARF6 stimulates beta-catenin transcriptional activity during WNT5A-mediated melanoma invasion and metastasis. Sci Signal 6:ra14

47. O'Connell MP, Fiori JL, Xu M, Carter AD, Frank BP, Camilli TC, French AD, Dissanayake SK, Indig FE, Bernier M, Taub DD, Hewitt SM, Weeraratna AT (2010) The orphan tyrosine kinase receptor, ROR2, mediates Wnt5A signaling in metastatic melanoma. Oncogene 29:34-44

48. Anastas JN, Kulikauskas RM, Tamir T, Rizos H, Long GV, von Euw EM, Yang PT, Chen HW, Haydu L, Toroni RA, Lucero OM, Chien AJ, Moon RT (2014) WNT5A enhances resistance of melanoma cells to targeted BRAF inhibitors. J Clin Invest 124:2877-2890

49. Nishita M, Itsukushima S, Nomachi A, Endo M, Wang Z, Inaba D, Qiao S, Takada S, Kikuchi A, Minami Y (2010) Ror2/Frizzled complex mediates Wnt5a-induced AP-1 activation by regulating Dishevelled polymerization. Mol Cell Biol 30:3610-3619

50. Hu B, Lefort K, Qiu W, Nguyen BC, Rajaram RD, Castillo E, He F, Chen Y, Angel P, Brisken C, Dotto GP (2010) Control of hair follicle cell fate by underlying mesenchyme through a CSLWnt5a-FoxN1 regulatory axis. Genes Dev 24:1519-1532

51. Sheldahl LC, Park M, Malbon CC, Moon RT (1999) Protein kinase $\mathrm{C}$ is differentially stimulated by Wnt and Frizzled homologs in a G-protein-dependent manner. Curr Biol 9:695-698

52. Slusarski DC, Corces VG, Moon RT (1997) Interaction of Wnt and a Frizzled homologue triggers G-protein-linked phosphatidylinositol signalling. Nature 390:410-413

53. Niu LJ, Xu RX, Zhang P, Du MX, Jiang XD (2012) Suppression of Frizzled-2-mediated $\mathrm{Wnt} / \mathrm{Ca}(2)(+)$ signaling significantly attenuates intracellular calcium accumulation in vitro and in a rat model of traumatic brain injury. Neuroscience 213:19-28

54. Chen W, ten Berge D, Brown J, Ahn S, Hu LA, Miller WE, Caron MG, Barak LS, Nusse R, Lefkowitz RJ (2003) Dishevelled 2 recruits beta-arrestin 2 to mediate Wnt5A-stimulated endocytosis of Frizzled 4. Science 301:1391-1394

55. Perry SJ, Lefkowitz RJ (2002) Arresting developments in heptahelical receptor signaling and regulation. Trends Cell Biol 12:130-138

56. Zhang A, He S, Sun X, Ding L, Bao X, Wang N (2014) Wnt5a promotes migration of human osteosarcoma cells by triggering a phosphatidylinositol-3 kinase/Akt signals. Cancer Cell Int 14:15 
57. Liu J, Zhang Y, Xu R, Du J, Hu Z, Yang L, Chen Y, Zhu Y, Gu L (2013) PI3K/Akt-dependent phosphorylation of GSK3beta and activation of RhoA regulate Wnt5a-induced gastric cancer cell migration. Cell Signal 25:447-456

58. Jung YS, Lee HY, Kim SD, Park JS, Kim JK, Suh PG, Bae YS (2013) Wnt5a stimulates chemotactic migration and chemokine production in human neutrophils. Exp Mol Med 45:e27

59. Halleskog C, Dijksterhuis JP, Kilander MB, Becerril-Ortega J, Villaescusa JC, Lindgren E, Arenas E, Schulte G (2012) Heterotrimeric G protein-dependent WNT-5A signaling to ERK1/2 mediates distinct aspects of microglia proinflammatory transformation. J Neuroinflamm 9:111

60. Kilander MB, Petersen J, Andressen KW, Ganji RS, Levy FO, Schuster J, Dahl N, Bryja V, Schulte G (2014) Disheveled regulates precoupling of heterotrimeric $\mathrm{G}$ proteins to Frizzled 6 . FASEB J 28:2293-2305

61. Aznar N, Midde KK, Dunkel Y, Lopez-Sanchez I, Pavlova Y, Marivin A, Barbazan J, Murray F, Nitsche U, Janssen KP, Willert K, Goel A, Abal M, Garcia-Marcos M, Ghosh P (2015) Daple is a novel non-receptor GEF required for trimeric $G$ protein activation in Wnt signaling. Elife 4:e07091. doi:10.7554/ eLife.07091

62. Schulte G (2010) International Union of Basic and Clinical Pharmacology. LXXX. The class Frizzled receptors. Pharmacol Rev 62:632-667

63. Ho HY, Susman MW, Bikoff JB, Ryu YK, Jonas AM, Hu L, Kuruvilla R, Greenberg ME (2012) Wnt5a-Ror-Dishevelled signaling constitutes a core developmental pathway that controls tissue morphogenesis. Proc Natl Acad Sci USA 109:4044-4051

64. Gao B, Song H, Bishop K, Elliot G, Garrett L, English MA, Andre P, Robinson J, Sood R, Minami Y, Economides AN, Yang Y (2011) Wnt signaling gradients establish planar cell polarity by inducing Vangl2 phosphorylation through Ror2. Dev Cell 20:163-176

65. Cheung R, Kelly J, Macleod RJ (2011) Regulation of villin by wnt5a/ror2 signaling in human intestinal cells. Front Physiol 2:58

66. Kikuchi A, Yamamoto H, Sato A, Matsumoto S (2012) Wnt5a: its signalling, functions and implication in diseases. Acta Physiol (Oxf) 204:17-33

67. Wang C, Zhao Y, Su Y, Li R, Lin Y, Zhou X, Ye L (2013) C-Jun N-terminal kinase (JNK) mediates Wnt5a-induced cell motility dependent or independent of RhoA pathway in human dental papilla cells. PLoS One 8:e69440

68. Nomachi A, Nishita M, Inaba D, Enomoto M, Hamasaki M, Minami Y (2008) Receptor tyrosine kinase Ror2 mediates Wnt5a-induced polarized cell migration by activating c-Jun $\mathrm{N}$-terminal kinase via actin-binding protein filamin A. J Biol Chem 283:27973-27981

69. Zhang X, Zhu J, Yang GY, Wang QJ, Qian L, Chen YM, Chen F, Tao Y, Hu HS, Wang T, Luo ZG (2007) Dishevelled promotes axon differentiation by regulating atypical protein kinase C. Nat Cell Biol 9:743-754

70. Ohno S (2007) Extrinsic Wnt signalling controls the polarity component aPKC. Nat Cell Biol 9:738-740

71. Li L, Hutchins BI, Kalil K (2009) Wnt5a induces simultaneous cortical axon outgrowth and repulsive axon guidance through distinct signaling mechanisms. J Neurosci 29:5873-5883

72. Andre P, Wang Q, Wang N, Gao B, Schilit A, Halford MM, Stacker SA, Zhang X, Yang Y (2012) The Wnt coreceptor Ryk regulates Wnt/planar cell polarity by modulating the degradation of the core planar cell polarity component Vangl2. J Biol Chem 287:44518-44525

73. Povinelli BJ, Nemeth MJ (2014) Wnt5a regulates hematopoietic stem cell proliferation and repopulation through the Ryk receptor. Stem Cells 32:105-115
74. Luo Y, Zheng C, Zhang J, Lu D, Zhuang J, Xing S, Feng J, Yang D, Yan X (2012) Recognition of CD146 as an ERM-binding protein offers novel mechanisms for melanoma cell migration. Oncogene 31:306-321

75. Witze ES, Litman ES, Argast GM, Moon RT, Ahn NG (2008) Wnt5a control of cell polarity and directional movement by polarized redistribution of adhesion receptors. Science 320:365-369

76. van Amerongen R, Fuerer C, Mizutani M, Nusse R (2012) Wnt5a can both activate and repress Wnt/beta-catenin signaling during mouse embryonic development. Dev Biol 369:101-114

77. Topol L, Jiang X, Choi H, Garrett-Beal L, Carolan PJ, Yang Y (2003) Wnt-5a inhibits the canonical Wnt pathway by promoting GSK-3-independent beta-catenin degradation. J Cell Biol 162:899-908

78. Griesmann H, Ripka S, Pralle M, Ellenrieder V, Baumgart S, Buchholz M, Pilarsky C, Aust D, Gress TM, Michl P (2013) WNT5A-NFAT signaling mediates resistance to apoptosis in pancreatic cancer. Neoplasia 15:11-22

79. Torii K, Nishizawa K, Kawasaki A, Yamashita Y, Katada M, Ito M, Nishimoto I, Terashita K, Aiso S, Matsuoka M (2008) Antiapoptotic action of Wnt5a in dermal fibroblasts is mediated by the PKA signaling pathways. Cell Signal 20:1256-1266

80. Okamoto M, Udagawa N, Uehara S, Maeda K, Yamashita T, Nakamichi Y, Kato H, Saito N, Minami Y, Takahashi N, Kobayashi Y (2014) Noncanonical Wnt5a enhances Wnt/betacatenin signaling during osteoblastogenesis. Sci Rep 4:4493

81. Bakker ER, Raghoebir L, Franken PF, Helvensteijn W, van Gurp L, Meijlink F, van der Valk MA, Rottier RJ, Kuipers EJ, van Veelen W, Smits R (2012) Induced Wnt5a expression perturbs embryonic outgrowth and intestinal elongation, but is welltolerated in adult mice. Dev Biol 369:91-100

82. Cervantes S, Yamaguchi TP, Hebrok M (2009) Wnt5a is essential for intestinal elongation in mice. Dev Biol 326:285-294

83. Lickert H, Kispert A, Kutsch S, Kemler R (2001) Expression patterns of Wnt genes in mouse gut development. Mech Dev 105:181-184

84. Yin C, Ciruna B, Solnica-Krezel L (2009) Convergence and extension movements during vertebrate gastrulation. Curr Top Dev Biol 89:163-192

85. Wallingford JB, Vogeli KM, Harland RM (2001) Regulation of convergent extension in Xenopus by Wnt5a and Frizzled-8 is independent of the canonical Wnt pathway. Int J Dev Biol 45:225-227

86. Yamanaka H, Moriguchi T, Masuyama N, Kusakabe M, Hanafusa H, Takada R, Takada S, Nishida E (2002) JNK functions in the non-canonical Wnt pathway to regulate convergent extension movements in vertebrates. EMBO Rep 3:69-75

87. Qian D, Jones C, Rzadzinska A, Mark S, Zhang X, Steel KP, Dai X, Chen P (2007) Wnt5a functions in planar cell polarity regulation in mice. Dev Biol 306:121-133

88. Min H, Danilenko DM, Scully SA, Bolon B, Ring BD, Tarpley JE, DeRose M, Simonet WS (1998) Fgf-10 is required for both limb and lung development and exhibits striking functional similarity to Drosophila branchless. Genes Dev 12:3156-3161

89. Pepicelli CV, Lewis PM, McMahon AP (1998) Sonic hedgehog regulates branching morphogenesis in the mammalian lung. Curr Biol 8:1083-1086

90. Miller LA, Wert SE, Clark JC, Xu Y, Perl AK, Whitsett JA (2004) Role of Sonic hedgehog in patterning of tracheal-bronchial cartilage and the peripheral lung. Dev Dyn 231:57-71

91. Bellusci S, Furuta Y, Rush MG, Henderson R, Winnier G, Hogan BL (1997) Involvement of Sonic hedgehog (Shh) in mouse embryonic lung growth and morphogenesis. Development 124:53-63 
92. Bellusci S, Henderson R, Winnier G, Oikawa T, Hogan BL (1996) Evidence from normal expression and targeted misexpression that bone morphogenetic protein (Bmp-4) plays a role in mouse embryonic lung morphogenesis. Development 122: $1693-1702$

93. Li C, Hu L, Xiao J, Chen H, Li JT, Bellusci S, Delanghe S, Minoo P (2005) Wnt5a regulates Shh and Fgf10 signaling during lung development. Dev Biol 287:86-97

94. Bodmer D, Levine-Wilkinson S, Richmond A, Hirsh S, Kuruvilla R (2009) Wnt5a mediates nerve growth factor-dependent axonal branching and growth in developing sympathetic neurons. J Neurosci 29:7569-7581

95. Blakely BD, Bye CR, Fernando CV, Horne MK, Macheda ML, Stacker SA, Arenas E, Parish CL (2011) Wnt5a regulates midbrain dopaminergic axon growth and guidance. PLoS One 6:e18373

96. Andersson ER, Salto C, Villaescusa JC, Cajanek L, Yang S, Bryjova L, Nagy II, Vainio SJ, Ramirez C, Bryja V, Arenas E (2013) Wnt5a cooperates with canonical Wnts to generate midbrain dopaminergic neurons in vivo and in stem cells. Proc Natl Acad Sci USA 110:E602-E610

97. Schleiffarth JR, Person AD, Martinsen BJ, Sukovich DJ, Neumann A, Baker CV, Lohr JL, Cornfield DN, Ekker SC, Petryk A (2007) Wnt5a is required for cardiac outflow tract septation in mice. Pediatr Res 61:386-391

98. Sinha T, Li D, Theveniau-Ruissy M, Hutson MR, Kelly RG, Wang J (2015) Loss of Wnt5a disrupts second heart field cell deployment and may contribute to OFT malformations in DiGeorge syndrome. Hum Mol Genet 24:1704-1716

99. Serra R, Easter SL, Jiang W, Baxley SE (2011) Wnt5a as an effector of TGFbeta in mammary development and cancer. J Mammary Gland Biol Neoplasia 16:157-167

100. Shimogori T, Banuchi V, Ng HY, Strauss JB, Grove EA (2004) Embryonic signaling centers expressing BMP, WNT and FGF proteins interact to pattern the cerebral cortex. Development 131:5639-5647

101. Andre P, Song H, Kim W, Kispert A, Yang Y (2015) Wnt5a and Wnt11 regulate mammalian anterior-posterior axis elongation. Development 142:1516-1527

102. Majumdar A, Vainio S, Kispert A, McMahon J, McMahon AP (2003) Wnt11 and Ret/Gdnf pathways cooperate in regulating ureteric branching during metanephric kidney development. Development 130:3175-3185

103. Nishita M, Yoo SK, Nomachi A, Kani S, Sougawa N, Ohta Y, Takada S, Kikuchi A, Minami Y (2006) Filopodia formation mediated by receptor tyrosine kinase Ror2 is required for Wnt5a-induced cell migration. J Cell Biol 175:555-562

104. Gupton SL (2007) Gertler FB (2007) Filopodia: the fingers that do the walking. Sci STKE 400:re5

105. Eyers CE, McNeill H, Knebel A, Morrice N, Arthur SJ, Cuenda A, Cohen P (2005) The phosphorylation of CapZ-interacting protein (CapZIP) by stress-activated protein kinases triggers its dissociation from CapZ. Biochem J 389:127-135

106. Huang C, Rajfur Z, Borchers C, Schaller MD, Jacobson K (2003) JNK phosphorylates paxillin and regulates cell migration. Nature 424:219-223

107. Wei W, Li H, Li N, Sun H, Li Q, Shen X (2013) WNT5A/JNK signaling regulates pancreatic cancer cells migration by phosphorylating Paxillin. Pancreatology 13:384-392

108. Ishida-Takagishi M, Enomoto A, Asai N, Ushida K, Watanabe T, Hashimoto T, Kato T, Weng L, Matsumoto S, Asai M, Murakumo Y, Kaibuchi K, Kikuchi A, Takahashi M (2012) The Dishevelled-associating protein Daple controls the non-canonical Wnt/Rac pathway and cell motility. Nat Commun 3:859

109. Zhu Y, Shen T, Liu J, Zheng J, Zhang Y, Xu R, Sun C, Du J, Chen Y, Gu L (2013) Rab35 is required for Wnt5a/Dvl2- induced Rac1 activation and cell migration in MCF-7 breast cancer cells. Cell Signal 25:1075-1085

110. Zhu Y, Tian Y, Du J, Hu Z, Yang L, Liu J, Gu L (2012) Dvl2dependent activation of Daam1 and RhoA regulates Wnt5a-induced breast cancer cell migration. PLoS One 7:e37823

111. Sugimura R, He XC, Venkatraman A, Arai F, Box A, Semerad C, Haug JS, Peng L, Zhong XB, Suda T, Li L (2012) Noncanonical Wnt signaling maintains hematopoietic stem cells in the niche. Cell 150:351-365

112. Nemeth MJ, Topol L, Anderson SM, Yang Y, Bodine DM (2007) Wnt5a inhibits canonical Wnt signaling in hematopoietic stem cells and enhances repopulation. Proc Natl Acad Sci USA 104:15436-15441

113. Bilkovski R, Schulte DM, Oberhauser F, Gomolka M, Udelhoven M, Hettich MM, Roth B, Heidenreich A, Gutschow C, Krone W, Laudes M (2010) Role of WNT-5a in the determination of human mesenchymal stem cells into preadipocytes. J Biol Chem 285:6170-6178

114. Takada I, Mihara M, Suzawa M, Ohtake F, Kobayashi S, Igarashi M, Youn MY, Takeyama K, Nakamura T, Mezaki Y, Takezawa S, Yogiashi Y, Kitagawa H, Yamada G, Takada S, Minami Y, Shibuya H, Matsumoto K, Kato S (2007) A histone lysine methyltransferase activated by non-canonical Wnt signalling suppresses PPAR-gamma transactivation. Nat Cell Biol 9:1273-1285

115. James AW (2013) Review of signaling pathways governing MSC osteogenic and adipogenic differentiation. Scientifica (Cairo) 2013:684736

116. Santos A, Bakker AD, de Blieck-Hogervorst JM, Klein-Nulend J (2010) WNT5A induces osteogenic differentiation of human adipose stem cells via rho-associated kinase ROCK. Cytotherapy 12:924-932

117. Liu A, Chen S, Cai S, Dong L, Liu L, Yang Y, Guo F, Lu X, He H, Chen Q, Hu S, Qiu H (2014) Wnt5a through noncanonical Wnt/JNK or Wnt/PKC signaling contributes to the differentiation of mesenchymal stem cells into type II alveolar epithelial cells in vitro. PLoS One 9:e90229

118. Villar J, Cabrera NE, Valladares F, Casula M, Flores C, Blanch L, Quilez ME, Santana-Rodriguez N, Kacmarek RM, Slutsky AS (2011) Activation of the Wnt/beta-catenin signaling pathway by mechanical ventilation is associated with ventilator-induced pulmonary fibrosis in healthy lungs. PLoS One 6:e23914

119. Levanen B, Wheelock AM, Eklund A, Grunewald J, Nord M (2011) Increased pulmonary Wnt (wingless/integrated)-signaling in patients with sarcoidosis. Respir Med 105:282-291

120. Igota S, Tosa M, Murakami M, Egawa S, Shimizu H, Hyakusoku H, Ghazizadeh M (2013) Identification and characterization of Wnt signaling pathway in keloid pathogenesis. Int J Med Sci 10:344-354

121. Rashid ST, Humphries JD, Byron A, Dhar A, Askari JA, Selley JN, Knight D, Goldin RD, Thursz M, Humphries MJ (2012) Proteomic analysis of extracellular matrix from the hepatic stellate cell line LX-2 identifies CYR61 and Wnt-5a as novel constituents of fibrotic liver. J Proteome Res 11:4052-4064

122. Jiang F, Parsons CJ, Stefanovic B (2006) Gene expression profile of quiescent and activated rat hepatic stellate cells implicates Wnt signaling pathway in activation. J Hepatol 45:401-409

123. Raghu G, Chen YY, Rusch V, Rabinovitch PS (1988) Differential proliferation of fibroblasts cultured from normal and fibrotic human lungs. Am Rev Respir Dis 138:703-708

124. Clarke DL, Carruthers AM, Mustelin T, Murray LA (2013) Matrix regulation of idiopathic pulmonary fibrosis: the role of enzymes. Fibrogenesis Tissue Repair 6:20

125. Ho C, Lee PH, Hsu YC, Wang FS, Huang YT, Lin CL (2012) Sustained Wnt/beta-catenin signaling rescues high glucose 
induction of transforming growth factor-beta1-mediated renal fibrosis. Am J Med Sci 344:374-382

126. Chaussabel D, Semnani RT, McDowell MA, Sacks D, Sher A, Nutman TB (2003) Unique gene expression profiles of human macrophages and dendritic cells to phylogenetically distinct parasites. Blood 102:672-681

127. Nanbara H, Wara-aswapati N, Nagasawa T, Yoshida Y, Yashiro R, Bando Y, Kobayashi H, Khongcharoensuk J, Hormdee D, Pitiphat W, Boch JA, Izumi Y (2012) Modulation of Wnt5a expression by periodontopathic bacteria. PLoS One 7:e34434

128. Christman MA 2nd, Goetz DJ, Dickerson E, McCall KD, Lewis CJ, Benencia F, Silver MJ, Kohn LD, Malgor R (2008) Wnt5a is expressed in murine and human atherosclerotic lesions. Am J Physiol Heart Circ Physiol 294:H2864-H2870

129. Zhao Y, Wang CL, Li RM, Hui TQ, Su YY, Yuan Q, Zhou XD, Ye L (2014) Wnt5a promotes inflammatory responses via nuclear factor $\mathrm{kB}(\mathrm{NF}-\mathrm{kB})$ and mitogen-activated protein kinase (MAPK) pathways in human dental pulp cells. J Biol Chem 289:21028-21039

130. Catalan V, Gomez-Ambrosi J, Rodriguez A, Perez-Hernandez AI, Gurbindo J, Ramirez B, Mendez-Gimenez L, Rotellar F, Valenti V, Moncada R, Marti P, Sola I, Silva C, Salvador J, Fruhbeck G (2014) Activation of non-canonical Wnt signaling through WNT5A in visceral adipose tissue of obese subjects is related to inflammation. J Clin Endocrinol Metab 99:E1407E1417

131. Sen M, Lauterbach K, El-Gabalawy H, Firestein GS, Corr M, Carson DA (2000) Expression and function of wingless and frizzled homologs in rheumatoid arthritis. Proc Natl Acad Sci USA 97:2791-2796

132. Naskar D, Maiti G, Chakraborty A, Roy A, Chattopadhyay D, Sen M (2014) Wnt5a-Rac1-NF-kappaB homeostatic circuitry sustains innate immune functions in macrophages. J Immunol 192:4386-4397

133. Maiti G, Naskar D, Sen M (2012) The Wingless homolog Wnt5a stimulates phagocytosis but not bacterial killing. Proc Natl Acad Sci USA 109:16600-16605

134. Yu CH, Nguyen TT, Irvine KM, Sweet MJ, Frazer IH, Blumenthal A (2014) Recombinant Wnt3a and Wnt5a elicit macrophage cytokine production and tolerization to microbial stimulation via Toll-like receptor 4. Eur J Immunol 44:1480-1490

135. Zhao C, Bu X, Wang W, Ma T, Ma H (2014) GEC-derived SFRP5 inhibits Wnt5a-induced macrophage chemotaxis and activation. PLoS One 9:e85058

136. Li B, Zhong L, Yang X, Andersson T, Huang M, Tang SJ (2011) WNT5A signaling contributes to Abeta-induced neuroinflammation and neurotoxicity. PLoS One 6:e22920

137. Kim J, Kim J, Kim DW, Ha Y, Ihm MH, Kim H, Song K, Lee I (2010) Wnt5a induces endothelial inflammation via beta-catenin-independent signaling. J Immunol 185:1274-1282

138. Halleskog C, Schulte G (2013) WNT-3A and WNT-5A counteract lipopolysaccharide-induced pro-inflammatory changes in mouse primary microglia. J Neurochem 125:803-808

139. Bergenfelz C, Medrek C, Ekstrom E, Jirstrom K, Janols H, Wullt M, Bredberg A, Leandersson K (2012) Wnt5a induces a tolerogenic phenotype of macrophages in sepsis and breast cancer patients. J Immunol 188:5448-5458

140. Clevers H, Nusse R (2012) Wnt/beta-catenin signaling and disease. Cell 149:1192-1205

141. Leris AC, Roberts TR, Jiang WG, Newbold RF, Mokbel K (2005) WNT5A expression in human breast cancer. Anticancer Res 25:731-734

142. Jonsson M, Dejmek J, Bendahl PO, Andersson T (2002) Loss of Wnt-5a protein is associated with early relapse in invasive ductal breast carcinomas. Cancer Res 62:409-416
143. Kremenevskaja N, von Wasielewski R, Rao AS, Schofl C, Andersson T, Brabant G (2005) Wnt-5a has tumor suppressor activity in thyroid carcinoma. Oncogene 24:2144-2154

144. Dejmek J, Dejmek A, Safholm A, Sjolander A, Andersson T (2005) Wnt-5a protein expression in primary dukes B colon cancers identifies a subgroup of patients with good prognosis. Cancer Res 65:9142-9146

145. Liang H, Chen Q, Coles AH, Anderson SJ, Pihan G, Bradley A, Gerstein R, Jurecic R, Jones SN (2003) Wnt5a inhibits B cell proliferation and functions as a tumor suppressor in hematopoietic tissue. Cancer Cell 4:349-360

146. Wang Q, Symes AJ, Kane CA, Freeman A, Nariculam J, Munson P, Thrasivoulou C, Masters JR, Ahmed A (2010) A novel role for $\mathrm{Wnt} / \mathrm{Ca}^{2+}$ signaling in actin cytoskeleton remodeling and cell motility in prostate cancer. PLoS One 5:e10456

147. Yamamoto H, Oue N, Sato A, Hasegawa Y, Yamamoto H, Matsubara A, Yasui W, Kikuchi A (2010) Wnt5a signaling is involved in the aggressiveness of prostate cancer and expression of metalloproteinase. Oncogene 29:2036-2046

148. Da Forno PD, Pringle JH, Hutchinson P, Osborn J, Huang Q, Potter L, Hancox RA, Fletcher A, Saldanha GS (2008) WNT5A expression increases during melanoma progression and correlates with outcome. Clin Cancer Res 14:5825-5832

149. Pourreyron C, Reilly L, Proby C, Panteleyev A, Fleming C, McLean K, South AP, Foerster J (2012) Wnt5a is strongly expressed at the leading edge in non-melanoma skin cancer, forming active gradients, while canonical Wnt signalling is repressed. PLoS One 7:e31827

150. Weeraratna AT, Jiang Y, Hostetter G, Rosenblatt K, Duray P, Bittner M, Trent JM (2002) Wnt5a signaling directly affects cell motility and invasion of metastatic melanoma. Cancer Cell $1: 279-288$

151. Bellon M, Ko NL, Lee MJ, Yao Y, Waldmann TA, Trepel JB, Nicot C (2013) Adult T-cell leukemia cells overexpress Wnt5a and promote osteoclast differentiation. Blood 121:5045-5054

152. Kaucka M, Plevova K, Pavlova S, Janovska P, Mishra A, Verner J, Prochazkova J, Krejci P, Kotaskova J, Ovesna P, Tichy B, Brychtova Y, Doubek M, Kozubik A, Mayer J, Pospisilova S, Bryja V (2013) The planar cell polarity pathway drives pathogenesis of chronic lymphocytic leukemia by the regulation of B-lymphocyte migration. Cancer Res 73:1491-1501

153. Tsukasaki K, Hermine O, Bazarbachi A, Ratner L, Ramos JC, Harrington W Jr, O'Mahony D, Janik JE, Bittencourt AL, Taylor GP, Yamaguchi K, Utsunomiya A, Tobinai $\mathrm{K}$, Watanabe $\mathrm{T}$ (2009) Definition, prognostic factors, treatment, and response criteria of adult T-cell leukemia-lymphoma: a proposal from an international consensus meeting. J Clin Oncol 27:453-459

154. Kiyokawa T, Yamaguchi K, Takeya M, Takahashi K, Watanabe T, Matsumoto T, Lee SY, Takatsuki K (1987) Hypercalcemia and osteoclast proliferation in adult T-cell leukemia. Cancer 59:1187-1191

155. Roman-Gomez J, Jimenez-Velasco A, Cordeu L, Vilas-Zornoza A, San Jose-Eneriz E, Garate L, Castillejo JA, Martin V, Prosper F, Heiniger A, Torres A, Agirre X (2007) WNT5A, a putative tumour suppressor of lymphoid malignancies, is inactivated by aberrant methylation in acute lymphoblastic leukaemia. Eur $\mathbf{J}$ Cancer 43:2736-2746

156. Li J, Ying J, Fan Y, Wu L, Ying Y, Chan AT, Srivastava G, Tao Q (2010) WNT5A antagonizes WNT/beta-catenin signaling and is frequently silenced by promoter $\mathrm{CpG}$ methylation in esophageal squamous cell carcinoma. Cancer Biol Ther 10:617-624

157. Kurayoshi $M$, Oue $N$, Yamamoto $H$, Kishida $M$, Inoue $A$, Asahara T, Yasui W, Kikuchi A (2006) Expression of Wnt-5a is correlated with aggressiveness of gastric cancer by stimulating cell migration and invasion. Cancer Res 66:10439-10448 
158. Hanaki H, Yamamoto H, Sakane H, Matsumoto S, Ohdan H, Sato A, Kikuchi A (2012) An anti-Wnt5a antibody suppresses metastasis of gastric cancer cells in vivo by inhibiting receptormediated endocytosis. Mol Cancer Ther 11:298-307

159. Yamamoto H, Kitadai Y, Yamamoto H, Oue N, Ohdan H, Yasui W, Kikuchi A (2009) Laminin gamma2 mediates Wnt5a-induced invasion of gastric cancer cells. Gastroenterology 137:242-252, 252.e1-6

160. Li S, Wang W, Zhang N, Ma T, Zhao C (2014) IL-1beta mediates MCP-1 induction by Wnt5a in gastric cancer cells. BMC Cancer 14:480

161. Huang Y, Liu G, Zhang B, Xu G, Xiong W, Yang H (2010) Wnt-5a regulates proliferation in lung cancer cells. Oncol Rep 23:177-181

162. Huang CL, Liu D, Nakano J, Ishikawa S, Kontani K, Yokomise $H$, Ueno M (2005) Wnt5a expression is associated with the tumor proliferation and the stromal vascular endothelial growth factor-an expression in non-small-cell lung cancer. J Clin Oncol 23:8765-8773

163. Hecht SS (1999) Tobacco smoke carcinogens and lung cancer. J Natl Cancer Inst 91:1194-1210

164. Whang YM, Jo U, Sung JS, Ju HJ, Kim HK, Park KH, Lee JW, Koh IS, Kim YH (2013) Wnt5a is associated with cigarette smoke-related lung carcinogenesis via protein kinase C. PLoS One 8:e53012

165. Dissanayake SK, Wade M, Johnson CE, O'Connell MP, Leotlela PD, French AD, Shah KV, Hewitt KJ, Rosenthal DT, Indig FE, Jiang Y, Nickoloff BJ, Taub DD, Trent JM, Moon RT, Bittner M, Weeraratna AT (2007) The Wnt5A/protein kinase C pathway mediates motility in melanoma cells via the inhibition of metastasis suppressors and initiation of an epithelial to mesenchymal transition. J Biol Chem 282:17259-17271

166. Linnskog R, Jonsson G, Axelsson L, Prasad CP, Andersson T (2014) Interleukin-6 drives melanoma cell motility through p38alpha-MAPK-dependent up-regulation of WNT5A expression. Mol Oncol 8:1365-1378

167. O'Connell MP, Fiori JL, Baugher KM, Indig FE, French AD, Camilli TC, Frank BP, Earley R, Hoek KS, Hasskamp JH, Elias EG, Taub DD, Bernier M, Weeraratna AT (2009) Wnt5A activates the calpain-mediated cleavage of filamin A. J Invest Dermatol 129:1782-1789

168. Thiele S, Rauner M, Goettsch C, Rachner TD, Benad P, Fuessel S, Erdmann K, Hamann C, Baretton GB, Wirth MP, Jakob F, Hofbauer LC (2011) Expression profile of WNT molecules in prostate cancer and its regulation by aminobisphosphonates. J Cell Biochem 112:1593-1600

169. Hart CA, Scott LJ, Bagley S, Bryden AA, Clarke NW, Lang SH (2002) Role of proteolytic enzymes in human prostate bone metastasis formation: in vivo and in vitro studies. Br J Cancer 86:1136-1142

170. Jin F, Qu X, Fan Q, Wang L, Tang T, Hao Y, Dai K (2013) Regulation of prostate cancer cell migration toward bone marrow stromal cell-conditioned medium by Wnt5a signaling. Mol Med Rep 8:1486-1492

171. Lee GT, Kang DI, Ha YS, Jung YS, Chung J, Min K, Kim TH, Moon KH, Chung JM, Lee DH, Kim WJ, Kim IY (2014) Prostate cancer bone metastases acquire resistance to androgen deprivation via WNT5A-mediated BMP-6 induction. $\mathrm{Br} \mathrm{J}$ Cancer 110:1634-1644

172. Ekstrom EJ, Bergenfelz C, von Bulow V, Serifler F, Carlemalm E, Jonsson G, Andersson T, Leandersson K (2014) WNT5A induces release of exosomes containing pro-angiogenic and immunosuppressive factors from malignant melanoma cells. Mol Cancer 13:88

173. Dissanayake SK, Olkhanud PB, O'Connell MP, Carter A, French AD, Camilli TC, Emeche CD, Hewitt KJ, Rosenthal DT,
Leotlela PD, Wade MS, Yang SW, Brant L, Nickoloff BJ, Messina JL, Biragyn A, Hoek KS, Taub DD, Longo DL, Sondak VK, Hewitt SM, Weeraratna AT (2008) Wnt5A regulates expression of tumor-associated antigens in melanoma via changes in signal transducers and activators of transcription 3 phosphorylation. Cancer Res 68:10205-10214

174. Sherwood V, Chaurasiya SK, Ekstrom EJ, Guilmain W, Liu Q, Koeck T, Brown K, Hansson K, Agnarsdottir M, Bergqvist M, Jirstrom K, Ponten F, James P, Andersson T (2014) WNT5Amediated beta-catenin-independent signalling is a novel regulator of cancer cell metabolism. Carcinogenesis 35:784-794

175. Sirott MN, Bajorin DF, Wong GY, Tao Y, Chapman PB, Templeton MA, Houghton AN (1993) Prognostic factors in patients with metastatic malignant melanoma. A multivariate analysis. Cancer 72:3091-3098

176. Zhao S, Ye X, Xiao L, Lian X, Feng Y, Li F, Li L (2014) MiR26a inhibits prostate cancer progression by repression of Wnt5a. Tumour Biol 35:9725-9733

177. Wang Q, Williamson M, Bott S, Brookman-Amissah N, Freeman A, Nariculam J, Hubank MJ, Ahmed A, Masters JR (2007) Hypomethylation of WNT5A, CRIP1 and S100P in prostate cancer. Oncogene 26:6560-6565

178. Camilli TC, Xu M, O'Connell MP, Chien B, Frank BP, Subaran S, Indig FE, Morin PJ, Hewitt SM, Weeraratna AT (2011) Loss of Klotho during melanoma progression leads to increased filamin cleavage, increased Wnt5A expression, and enhanced melanoma cell motility. Pigment Cell Melanoma Res 24:175-186

179. Ying J, Li H, Yu J, Ng KM, Poon FF, Wong SC, Chan AT, Sung JJ, Tao Q (2008) WNT5A exhibits tumor-suppressive activity through antagonizing the Wnt/beta-catenin signaling, and is frequently methylated in colorectal cancer. Clin Cancer Res 14:55-61

180. Li Q, Chen H (2012) Silencing of Wnt5a during colon cancer metastasis involves histone modifications. Epigenetics 7:551-558

181. Rawson JB, Mrkonjic M, Daftary D, Dicks E, Buchanan DD, Younghusband HB, Parfrey PS, Young JP, Pollett A, Green RC, Gallinger S, McLaughlin JR, Knight JA, Bapat B (2011) Promoter methylation of Wnt5a is associated with microsatellite instability and BRAF V600E mutation in two large populations of colorectal cancer patients. Br J Cancer 104:1906-1912

182. Hibi K, Mizukami H, Goto T, Kitamura Y, Sakata M, Saito M, Ishibashi K, Kigawa G, Nemoto H, Sanada Y (2009) WNT5A gene is aberrantly methylated from the early stages of colorectal cancers. Hepatogastroenterology 56:1007-1009

183. Wang Z, Chen H (2010) Genistein increases gene expression by demethylation of WNT5a promoter in colon cancer cell line SW1116. Anticancer Res 30:4537-4545

184. Bakker ER, Das AM, Helvensteijn W, Franken PF, Swagemakers S, van der Valk MA, ten Hagen TL, Kuipers EJ, van Veelen W, Smits R (2013) Wnt5a promotes human colon cancer cell migration and invasion but does not augment intestinal tumorigenesis in Apc1638N mice. Carcinogenesis 34:26292638

185. Liu B, Tahk S, Yee KM, Yang R, Yang Y, Mackie R, Hsu C, Chernishof V, O'Brien N, Jin Y, Fan G, Lane TF, Rao J, Slamon D, Shuai K (2014) PIAS1 regulates breast tumorigenesis through selective epigenetic gene silencing. PLoS One 9:e89464

186. Cai J, Guan H, Fang L, Yang Y, Zhu X, Yuan J, Wu J, Li M (2013) MicroRNA-374a activates Wnt/beta-catenin signaling to promote breast cancer metastasis. J Clin Invest 123:566-579

187. Jonsson M, Andersson T (2001) Repression of Wnt-5a impairs DDR1 phosphorylation and modifies adhesion and migration of mammary cells. J Cell Sci 114:2043-2053

188. Medrek C, Landberg G, Andersson T, Leandersson K (2009) Wnt-5a-CKI $\{$ alpha $\}$ signaling promotes $\{$ beta $\}$-catenin/E- 
cadherin complex formation and intercellular adhesion in human breast epithelial cells. J Biol Chem 284:10968-10979

189. Prasad CP, Chaurasiya SK, Axelsson L, Andersson T (2013) WNT-5A triggers Cdc42 activation leading to an ERK1/2 dependent decrease in MMP9 activity and invasive migration of breast cancer cells. Mol Oncol 7:870-883

190. Safholm A, Leandersson K, Dejmek J, Nielsen CK, Villoutreix BO, Andersson T (2006) A formylated hexapeptide ligand mimics the ability of Wnt-5a to impair migration of human breast epithelial cells. J Biol Chem 281:2740-2749

191. Safholm A, Tuomela J, Rosenkvist J, Dejmek J, Harkonen P, Andersson T (2008) The Wnt-5a-derived hexapeptide Foxy-5 inhibits breast cancer metastasis in vivo by targeting cell motility. Clin Cancer Res 14:6556-6563

192. Hansen C, Howlin J, Tengholm A, Dyachok O, Vogel WF, Nairn AC, Greengard P, Andersson T (2009) Wnt-5a-induced phosphorylation of DARPP-32 inhibits breast cancer cell migration in a CREB-dependent manner. $J$ Biol Chem 284:27533-27543

193. Pukrop T, Klemm F, Hagemann T, Gradl D, Schulz M, Siemes S, Trumper L, Binder C (2006) Wnt 5a signaling is critical for macrophage-induced invasion of breast cancer cell lines. Proc Natl Acad Sci USA 103:5454-5459

194. Pukrop T, Dehghani F, Chuang HN, Lohaus R, Bayanga K, Heermann S, Regen T, Van Rossum D, Klemm F, Schulz M, Siam L, Hoffmann A, Trumper L, Stadelmann C, Bechmann I, Hanisch UK, Binder C (2010) Microglia promote colonization of brain tissue by breast cancer cells in a Wnt-dependent way. Glia 58:1477-1489

195. Jenei V, Sherwood V, Howlin J, Linnskog R, Safholm A, Axelsson L, Andersson T (2009) A t-butyloxycarbonyl-modified Wnt5a-derived hexapeptide functions as a potent antagonist of Wnt5a-dependent melanoma cell invasion. Proc Natl Acad Sci USA 106:19473-19478

196. Laeremans H, Hackeng TM, van Zandvoort MA, Thijssen VL, Janssen BJ, Ottenheijm HC, Smits JF, Blankesteijn WM (2011) Blocking of frizzled signaling with a homologous peptide fragment of wnt $3 \mathrm{a} / \mathrm{wnt} 5 \mathrm{a}$ reduces infarct expansion and prevents the development of heart failure after myocardial infarction. Circulation 124:1626-1635 